\title{
Two novel strategies to assess in vivo meiotic protein
}

\section{expression in Arabidopsis thaliana [version 1; peer review: 3}

\section{approved with reservations]}

\author{
Niels van Tol (iD*, Martijn Rolloos*, Paul J.J. Hooykaas, Bert J. van der Zaal \\ Department of Molecular and Developmental Genetics, Institute of Biology Leiden, Leiden, 2333 BE, The Netherlands \\ * Equal contributors
}

\section{V1 First published: 24 Apr 2019, 8:539 \\ https://doi.org/10.12688/f1000research.17954.1}

Latest published: 24 Apr 2019, 8:539

https://doi.org/10.12688/f1000research.17954.1

\begin{abstract}
For studies on key meiotic processes such as crossover formation and genome haploidization, the availability of portable promoter sequences for effector protein expression in meiocytes is of great importance. In this study, we present two novel strategies to facilitate screening for such promoter elements. The first strategy was based on expression of a previously constructed GFP-tagged zinc finger protein for visualization of the pericentromeric regions of chromosomes in meiocytes. Here, we show that expression of this reporter protein under control of different promoters allowed for the visualization of fluorescence foci in meiocytes, demonstrating that this is a useful tool for such purposes. The second reporter system was based on the visualization of cytotoxicity triggered by expression of the Agrobacterium tumefaciens virulence protein VirD5. We show that constitutive expression of VirD5 is lethal, but when driven by meiotic promoters led to reduced fertility with normal vegetative growth. We show that both strategies offer useful tools for the assessment of meiotic effector protein expression, especially when combined with available gene expression data sets.
\end{abstract}

\section{Keywords}

Arabidopsis, meiosis, gene expression, promoter, meiocytes, zinc finger, fluorescence reporter, negative selection marker

\section{Open Peer Review

\begin{tabular}{lccc} 
Approval Status & $? ? ?$ \\
& 1 & 2 & 3 \\
\hline version 1 & $?$ & $?$ & $?$ \\
24 Apr 2019 & view & view & view
\end{tabular} \\ 1. Christophe Lambing, University of Cambridge, Cambridge, UK \\ 2. Christine Mézard (D), University of Paris- Saclay, Versailles, France \\ Laurence Cromer, Jean-Pierre Bourgin Institute (IJPB), INRA, AgroParisTech, CNRS, University of Paris-Saclay, Versailles, France 3. Monica Pradillo ID, Complutense University of Madrid, Madrid, Spain}

Any reports and responses or comments on the article can be found at the end of the article. 
Corresponding author: Bert J. van der Zaal (b.j.v.d.zaal@biology.leidenuniv.nl)

Author roles: van Tol N: Data Curation, Formal Analysis, Investigation, Project Administration, Validation, Visualization, Writing Original Draft Preparation; Rolloos M: Conceptualization, Data Curation, Formal Analysis, Funding Acquisition, Investigation, Methodology, Project Administration, Validation, Visualization; Hooykaas PJj: Conceptualization, Funding Acquisition, Project Administration, Supervision, Writing - Review \& Editing; van der Zaal BJ: Conceptualization, Funding Acquisition, Methodology, Project Administration, Resources, Supervision, Writing - Review \& Editing

Competing interests: No competing interests were disclosed.

Grant information: This research was supported by a partnership between Rijk Zwaan and the Dutch Technology Foundation STW (partnership project number 12427), which is the applied science division of NWO, and the Technology Programme of the Ministry of Economic Affairs, Agriculture and Innovation.

Copyright: (c) 2019 van Tol $\mathrm{N}$ et al. This is an open access article distributed under the terms of the Creative Commons Attribution License, which permits unrestricted use, distribution, and reproduction in any medium, provided the original work is properly cited.

How to cite this article: van Tol N, Rolloos M, Hooykaas PJJ and van der Zaal BJ. Two novel strategies to assess in vivo meiotic protein expression in Arabidopsis thaliana [version 1; peer review: 3 approved with reservations] F1000Research 2019, 8:539 https://doi.org/10.12688/f1000research.17954.1

First published: 24 Apr 2019, 8:539 https://doi.org/10.12688/f1000research.17954.1 


\section{Introduction}

The cell division process of meiosis generates haploid gametes for fertilization. Cells that are primed for meiosis (meiocytes) undergo two consecutive rounds of chromosome segregation. The first division (meiosis I) results in separation of the homologous chromosomes ${ }^{1}$, which is facilitated by the formation of physical connections (chiasmata) at double stranded break sites generated by transesterases, such as SPO11-12,3 and SPO11-2 ${ }^{4}$ in the model plant species Arabidopsis thaliana. Resolution of these junctions can lead to the reciprocal exchange of parts of chromosome arms, a process known as meiotic crossing over ${ }^{5}$. The second round of division (meiosis II), results in separation of the sister chromatids ${ }^{1}$, finally yielding four haploid daughter cells from a diploid meiocyte. In Arabidopsis, male and female meiosis are separated within the flower and take place in the anthers and carpels, respectively. Male meiocytes are organized as column-like structures (referred to in this study as male meiocyte columns) ${ }^{6,7}$, and upon completion of meiosis give rise to four haploid pollen cells that are physically attached to each other as structures known as tetrads. Maturation of tetrads eventually leads to the release of individual pollen cells.

The process of meiosis is of great interest to plant breeders for different reasons. Most importantly, crossover events are the driving force behind genetic variation in plants ${ }^{5,8,9}$. Research on crossover frequency has thus received a considerable amount of attention in literature (e.g. 10-12). To facilitate the engineering of crossover-related events in meiocytes without affecting nonmeiotic tissue, there is interest in identifying gene promoters that allow for effector activity during meiosis. Although there is a vast amount of literature available on the genetics and cytogenetics of plant meiosis ${ }^{1}$, it has been challenging to identify DNA sequences that can be used to express proteins of interest preferably in meiotic cells.

Relatively recent studies on the male meiocyte transcriptome ${ }^{6,13}$ have provided cues for the identification of genes that are more or less specifically expressed during male meiosis. The upstream regions of these genes (generally representing the gene control region $^{14}$ ) are mostly referred to as 'promoters'. Such promoters can be regarded as portable elements for the assembly of gene expression cassettes that can mediate meiotic effector protein expression. Accurately quantifying meiotic transgene expression, however, is subject to a number of practical limitations. Firstly, relative expression levels do not necessarily correlate with promoter activity, which is determined by endogenous RNA metabolism as well (e.g. 15). Secondly, the isolation of meiocytes for quantitative gene expression analysis is technically very challenging and laborious, and could easily result in contamination of RT-qPCR or transcriptome data with non-meiocyte transcripts. Qualitative assessment of promoter activity using fluorescence microscopy is an attractive possibility. However, the dynamic cytoplasmic and nuclear states of meiocytes make it difficult to determine the exact localization of fluorescence, and to distinguish it from autofluorescence.

In this study, we have investigated two novel strategies to screen for portable promoter elements to express effector proteins specifically or at high levels in meiocytes. The first strategy was based on expressing a previously constructed GFP-tagged zinc finger protein (1803F-GFP) to visualize pericentromeric fluorescence foci in meiocytes. Here, we show that 1803F-GFP expression driven by the promoter of the Arabidopsis RPS5A gene ( $p$ RPS5A) which is active in vegetative ${ }^{16-18}$ and meristematic tissue $^{18}$, resulted in clear GFP foci in male meiocytes. We also selected and cloned 14 promoter sequences that could be of interest for expression of transgenes in meiocytes based on published transcriptome data, and assessed their activities in meiocytes using the $1803 \mathrm{~F}-\mathrm{GFP}$ reporter system. As a second strategy, we assembled constructs encoding the highly cytotoxic Agrobacterium tumefaciens virulence protein VirD5, which was recently shown to disturb chromosome segregation in plant cells by interacting with the kinetochores of chromosomes ${ }^{19}$. We reasoned that, due its mode of cytotoxicity, VirD5 could be used as a novel negative selection marker to assess effector protein expression in meiocytes. Here, we show that the VirD5 reporter system can be used to obtain in planta cues about promoter strength and specificity. Altogether, our data show that both strategies can provide valuable in vivo information regarding promoter activity in meiocytes.

\section{Results}

Molecular cloning of candidate promoters for meiotic protein expression analyses

To investigate the activity and specificity of promoters of interest to drive effector protein expression in meiocytes, we first cloned the promoters of a selection of genes which are involved in meiosis or highly expressed in meiocytes. In total, we cloned the promoter sequences of 14 genes based on the two available studies on the male meiocyte transcriptome ${ }^{6,13}$. An overview of these 14 genes is provided in Table 1 . In brief, we firstly selected five genes with important roles in meiosis (ZYP1A, SPO11-2, NBS1, SPO11-1, MUS81) that are expressed in male meiocytes ${ }^{6,13}$, and rather specifically so based on meiocyte/anther and meiocyte/seedling expression ratios $^{6}$ (Table 1). In addition, we selected four genes (ASK1,DMC1, SMC1 and MS5) which are involved in meiosis and are expressed in male meiocytes ${ }^{6,13}$, but not specifically so (Table 1). Secondly, we selected four genes (At1g27710, At5g25980, At5g26622, At5g42530) which are the most highly expressed genes in male meiocytes (13 and personal communications with the authors). Finally, we selected the promoter of the gene At4g40020, which has been described to be expressed specifically during meiosis $\mathrm{I}^{7}$.

\section{Establishing the 1803F-GFP reporter system to visualize meiotic protein expression}

Previously, we have described a GFP-based reporter to monitor chromosomes in vivo in vegetative tissue of Arabidopsis plants ${ }^{20}$. This construct encoded a fusion between the fluorescent protein GFP and an array of three zinc fingers (3F) targeting a cognate 9 bp DNA sequence ${ }^{14}$ in the highly conserved pericentromeric $178 \mathrm{bp}$ repeats which make up a large portion of the pericentromeric DNA in Arabidopsis ${ }^{21}$. Expression of this fusion protein, which is referred to here as '1803F-GFP', can result in distinctive GFP signals that visualize the pericentromeric regions of chromosomes or the cytological chromocenters ${ }^{20,22}$. 


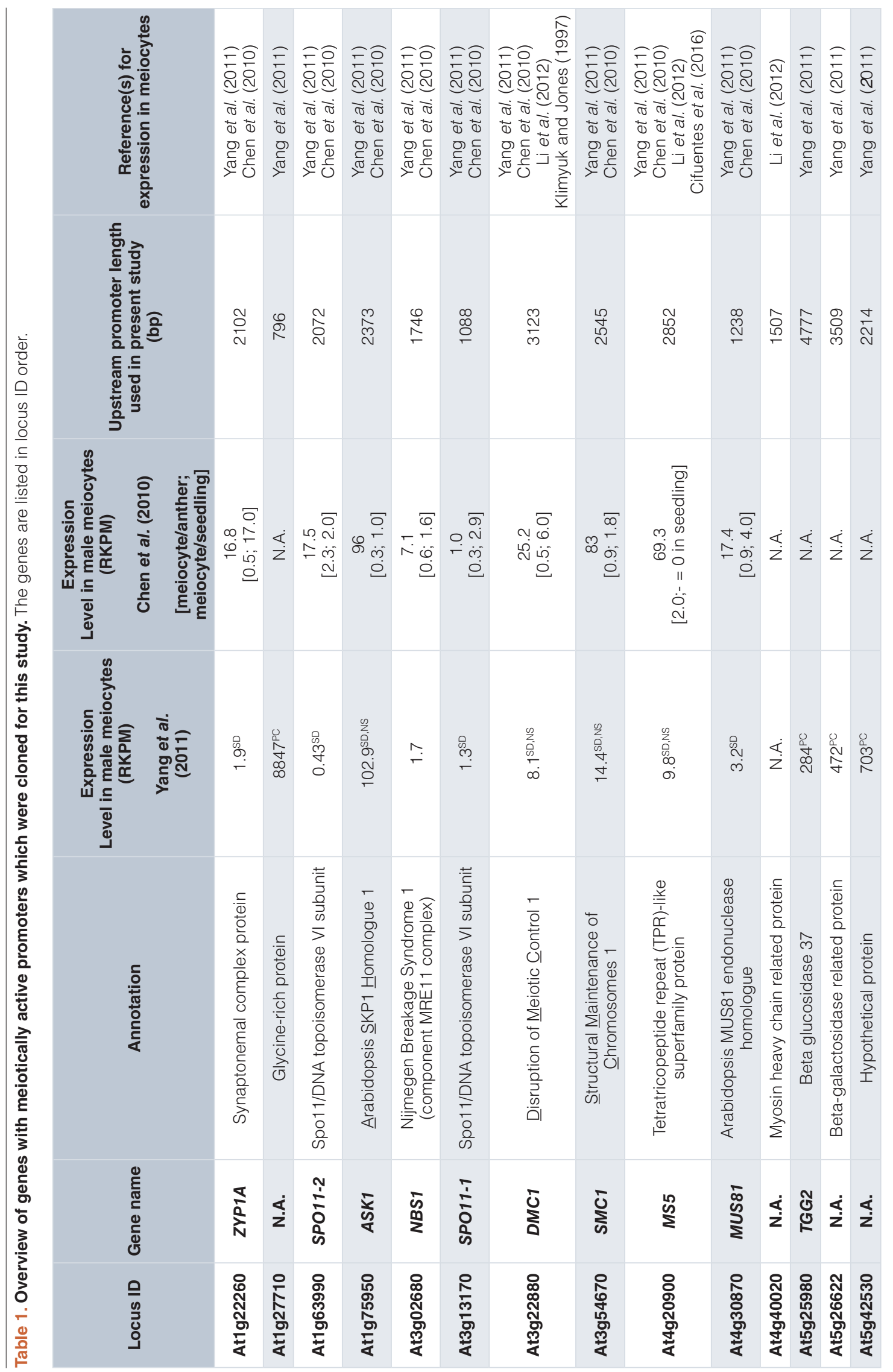


These signals are particularly easy to observe in non-green tissues, such as roots ${ }^{22}$. An important benefit of the formation of foci is that the GFP signal is strongly concentrated, making discrimination from autofluorescence much easier compared to the detection of diffuse GFP signal. In addition, as the $178 \mathrm{bp}$ repeat regions are strongly conserved and present in the pericentromeric regions of all five Arabidopsis chromosomes, the $1803 \mathrm{~F}-\mathrm{GFP}$ reporter system also allows for ploidy determination. For these reasons, we considered the 1803F-GFP system a suitable read-out for meiotic protein expression. An overview of the 1803F-GFP strategy is provided in Figure 1.

Previously, we have used the 1803 F-GFP reporter system ${ }^{20,22}$ under control of the promoter of the Arabidopsis RPS5A gene ( $p R P S 5 A)$ in the binary vector pRF 1803F:GFP Kana. For this study, we slightly modified the backbone of pRF 1803F:GFP Kana to accommodate the introduction of other promoter fragments. In addition, we introduced a new, flexible hydrophilic (GGGGS) linker ${ }^{23,24}$ to possibly enhance the read-out of the $1803 \mathrm{~F}-\mathrm{GFP}$ system. This newly generated binary vector was named pRF 1803F:(GGGGS) $)_{3}$ :GFP Kana. More details about the construction of pRF 1803F:(GGGGS) 3 :GFP Kana are provided in the Methods section. An overview of the DNA sequence and the key components of pRF 1803F:(GGGS) :GFP Kana is provided in Figure 2, and the amino acid sequence encoded by the $1803 \mathrm{~F}:(G G G G S)_{3}$ : GFP open reading frame is provided in Figure 3.

Promoters of interest can easily be introduced into the pRF 1803F:(GGGGS) $)_{3}$ :GFP Kana backbone, for instance by ligating SalI-NotI fragments of PCR-amplified promoter sequences into SalI-NotI digested pRF 1803F-GFP Kana, thereby directly placing the $1803 \mathrm{~F}-\mathrm{GFP}$ open reading frame under their
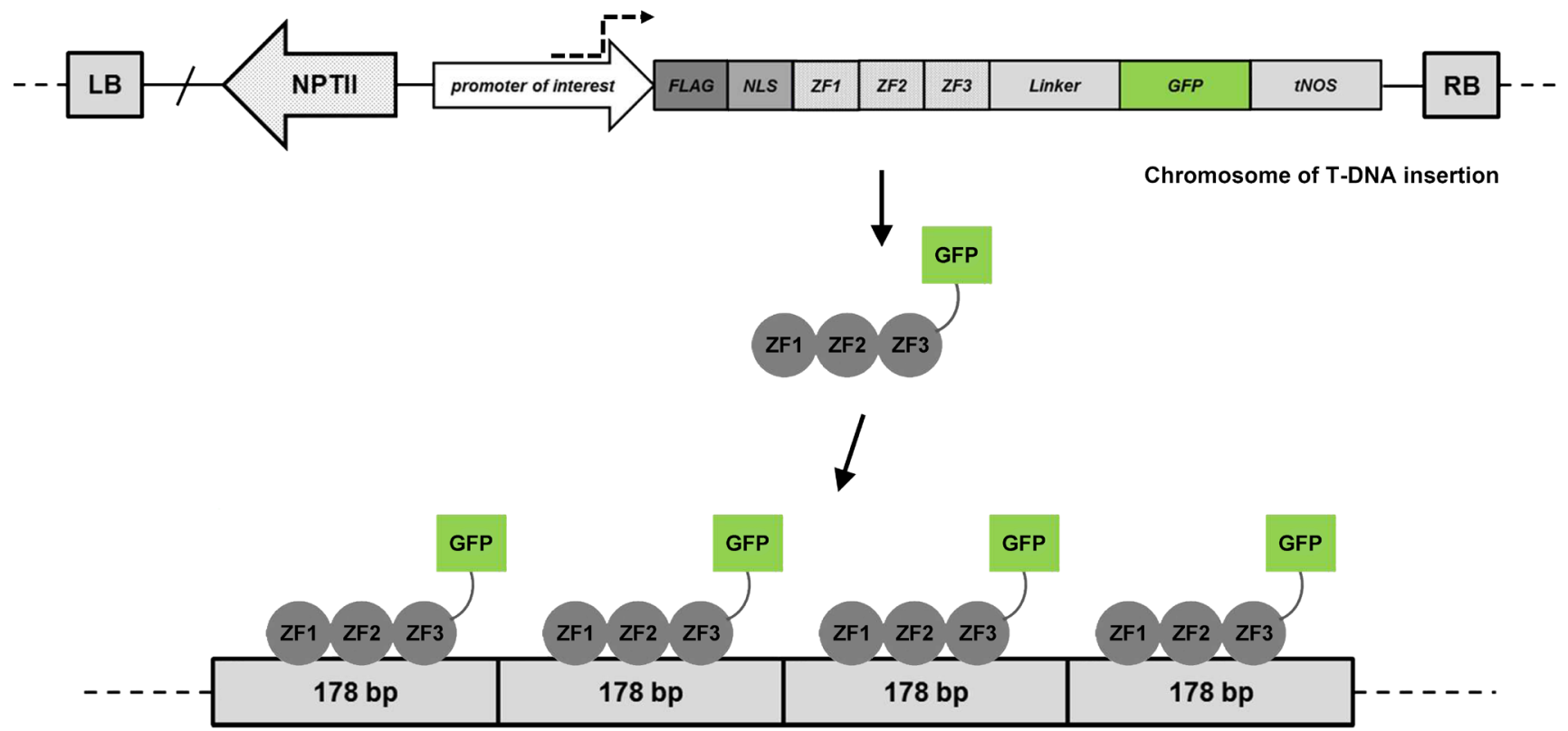

Pericentromeric region of any chromosome

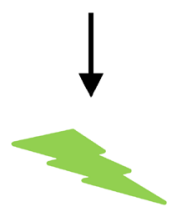

Green fluorescence foci for each chromosome

Figure 1. Screening for activity of promoters of interest using the 1803F-GFP reporter system. A promoter of interest (promoter of interest) is cloned into the binary vector pRF 1803F:(GGGGS): GFP Kana (e.g. as a PCR-amplified Sall-Notl fragment). The promoter drives expression of a fusion protein consisting of three zinc fingers (ZF1, ZF2 and ZF3) together recognizing 9 bp of DNA which are unique to a major fraction of the $178 \mathrm{bp}$ pericentromeric repeats, fused to the open reading frame of GFP (GFP), spaced by a flexible linker peptide (Linker), and with an N-terminal nuclear localization signal (NLS) and FLAG tag (FLAG). Transcription termination is under control of the NOS terminator sequence (tNOS). The construct is introduced into Arabidopsis plants as a T-DNA with left and right border sequences (LB and RB, respectively), through Agrobacterium tumefaciens-mediated transformation. Primary transformants are selected for by kanamycin resistance due to NPTI/ expression. Expression of 1803F-GFP under control of the promoter of interest can subsequently be visualized as nuclear GFP foci by microscopy. 


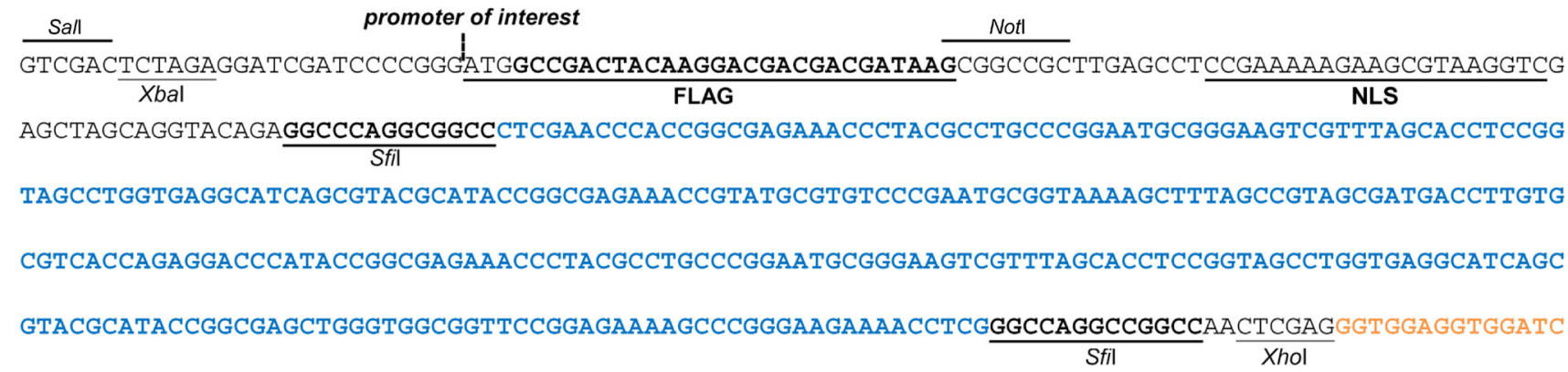
CGGAGGAGGAGGTTCGGGAGGCGGAGGTTCAACTAGTGTGAGCAAGGGCGAGGAGCTGTTCACCGGGGTGGTGCCCATCCTGGTCGAGCTGGAC GGCGACGTAAACGGCCACAAGTTCAGCGTGTCCGGCGAGGGCGAGGGCGATGCCACCTACGGCAAGCTGACCCTGAAGTTCATCTGCACCACCG GCAAGCTGCCCGTGCCCTGGCCCACCCTCGTGACCACCTTCACCTACGGCGTGCAGTGCTTCAGCCGCTACCCCGACCACATGAAGCAGCACGA СTTCTTCAAGTCCGCCATGCCCGAAGGCTACGTCCAGGAGCGCACCATCTTCTTCAAGGACGACGGCAACTACAAGACCCGCGCCGAGGTGAAG TTCGAGGGCGACACCCTGGTGAACCGCATCGAGCTGAAGGGCATCGACTTCAAGGAGGACGGCAACATCCTGGGGCACAAGCTGGAGTACAACT ACAACAGCCACAACGTCTATATCATGGCCGACAAGCAGAAGAACGGCATCAAGGTGAACTTCAAGATCCGCCACAACATCGAGGACGGCAGCGT GCAGCTCGCCGACCACTACCAGCAGAACACCCCCATCGGCGACGGCCCCGTGCTGCTGCCCGACAACCACTACCTGAGCACCCAGTCCGCCCTG AGCAAAGACCCCAACGAGAAGCGCGATCACATGGTCCTGCTGGAGTTCGTGACCGCCGCCGGGATCACTCTCGGCATGGACGAGCTGTACAAGT AAGAGCTCGAATTTCCCGATCGTTCAAACATTTGGCAATAAAGTTTCTTAAGATTGAATCCTGTTGCCGGTCTTGCGATGATTATCATATAAT TTCTGTTGAATACGTTAACATGTAATAATTAACATGTAATGCATGACGTTATTTATGAGATGGGTTTTATGATTAGAGTCCCGCAATTATA CATTTAATACGCGATAGAAAACAAAATATAGCGCGCAAACTAGGATAAATTATCGCGCGCGGTGTCATCTATGTTACTAGATCGGG

Figure 2. The DNA sequence of the 1803F-GFP fusion construct encoded on the binary vector pRF 1803F:(GGGGS) :GFP Kana. The fusion construct consists of the 1803F encoding sequence (bold blue font) flanked by Sfil sites, fused to the eGFP encoding sequence (bold green font) through a flexible linker (bold orange font), tagged with a FLAG tag and a nuclear localization signal (NLS) at the 5' end. Other relevant unique restriction sites are also indicated. Expression of the fusion construct is under control of a promoter of interest, which can be inserted at the indicated position, and of the NOS terminator sequence (bold grey font).

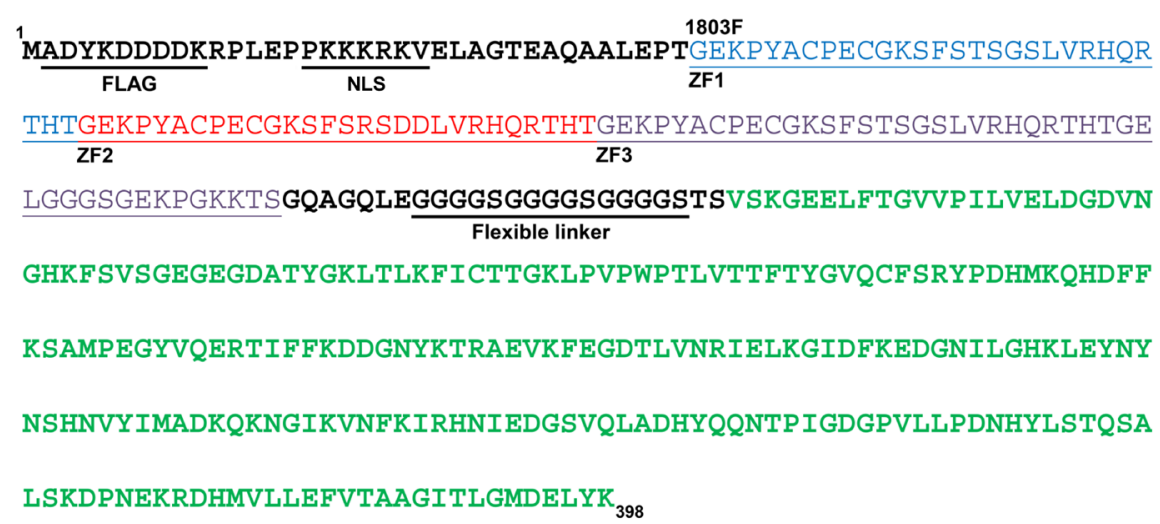

Figure 3. The amino acid sequence of the 1803F-GFP reporter protein. The fusion protein consists of 1803 F (consisting of three ZFs; ZF1 in blue, ZF2 in red and ZF3 in purple font, respectively) fused to GFP (bold green font) through a flexible linker peptide consisting of a trimer of the aa sequence GGGGS, and tagged with a FLAG tag and a nuclear localization signal (NLS) at the N-terminus (398 amino acids in total). 
control. The binary vector is also compatible with other cloning strategies, e.g. as described in this study for pSPO11 (further details described in the Methods section).

Visualization of promoter activity in meiocytes using the 1803F-GFP reporter system driven by the RPS5A promoter

To investigate the 1803F-GFP system as a novel tool to visualize protein expression in vivo in meiocytes, we firstly verified whether the nuclear GFP foci distinct for 1803F-GFP binding to pericentromeric regions (Figure 1) could be observed in root tip cells (diploid; $2 \mathrm{n}=10$ ) of transgenic plants harboring the $p R P S 5 A:: 1803 F:(G G G G S)_{3}: G F P$ construct. Nuclei of root tip cells could easily be visualized as expected, and in most cases contained ten distinct GFP foci in a full $Z$-stack of images, corresponding to the diploid $(2 n=10)$ number of chromosomes (Figure $4 \mathrm{~A})$. The foci could be examined directly by zooming in on confocal microscopy images and did not require further image analysis.
A
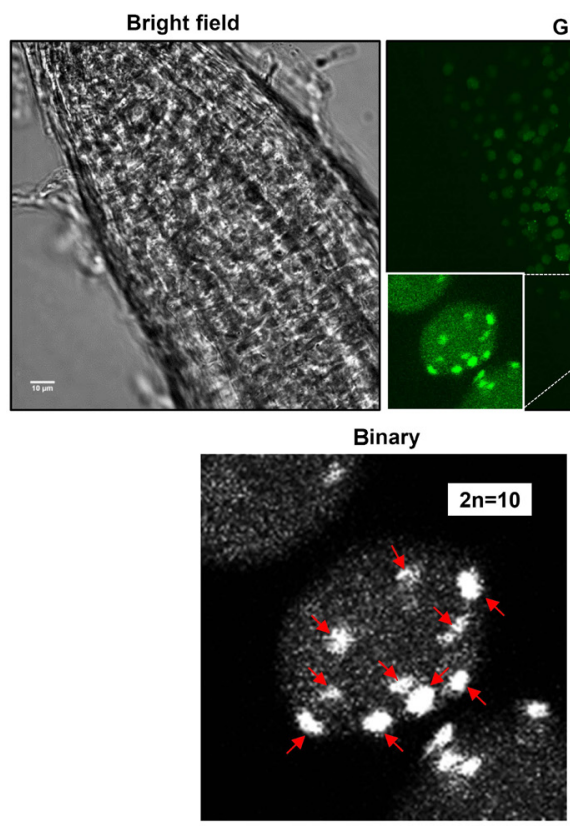

C

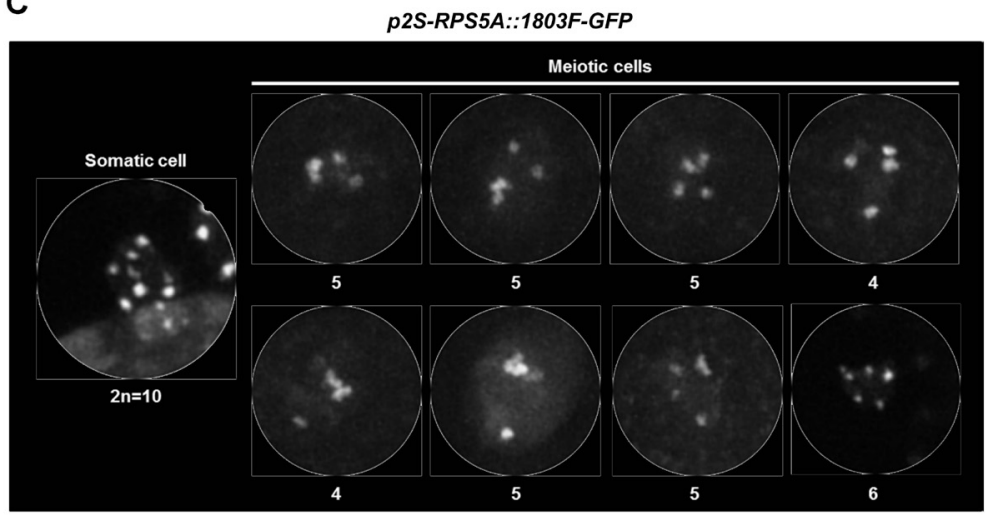

B GFP

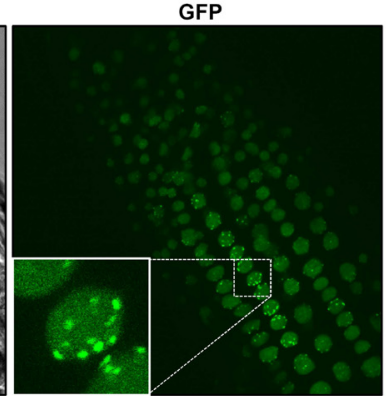

Bright
field

GFP

$\begin{array}{ccc}\text { Col-0 } & \text { pRPS5A::1803F-GFP } & \text { pRPS5A::GAL4-VP16 } \\ & \text { p35S-UAS::1803F-GFP }\end{array}$
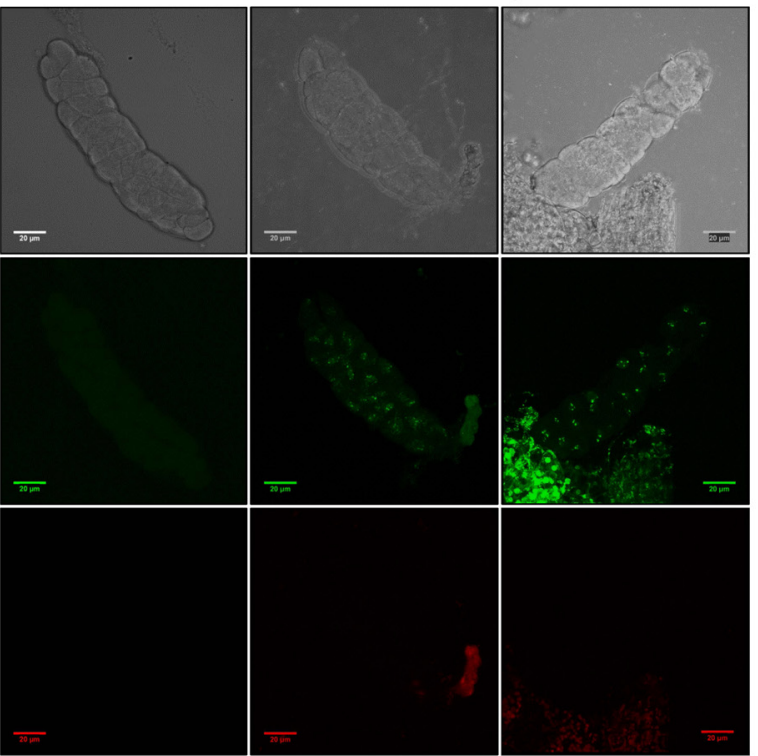

D

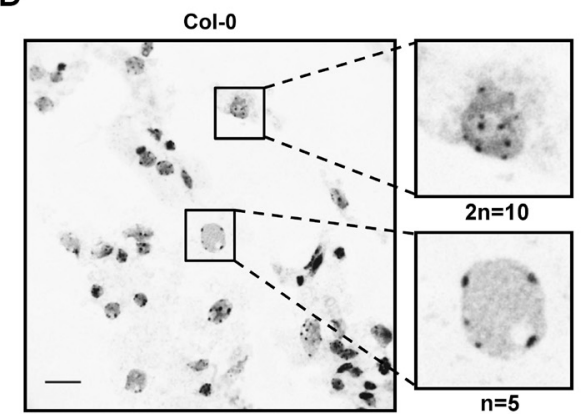

Figure 4. The 1803F-GFP reporter system in somatic and meiotic cells. (A) Confocal fluorescence microscopy images of a root tip (T2 generation) expressing 1803F-GFP under control of pRPS5A. Highlighted is a nucleus in which 10 distinct GFP foci corresponding to the diploid number of chromosomes $(2 \mathrm{n}=10)$ are visible. Scale bar represents $10 \mu \mathrm{M}$. A contrasted black and white ('Binary') version of the GFP image is included to clearly mark GFP-fluorescent chromocenters with red arrows. (B) Confocal fluorescence microscopy images of male meiocytes of wild-type Col-0 plants, primary transformants (T1 generation) expressing 1803F-GFP under control of the RPS5A promoter (pRPS5A::1803F-GFP), and primary transformants expressing 1803F-GFP under control of the GAL4-based two-step expression system (p2S-RPS5A::1803F-GFP). Images taken with the RFP channel are presented as negative controls for autofluorescence. Scale bars represent $20 \mu \mathrm{M}$. (C) False color images of nuclei of meiocytes harboring p2S-RPS5A::1803F-GFP ( $\mathrm{n}=8$ presented). Below every nucleus the number of counted GFP foci is presented. A diploid somatic cell $(2 n=10)$ is provided as a control. (D) DAPI-stained spread of wild-type Col-0 flower bud tissue. Highlighted are a diploid cell $(2 n=10)$ and a haploid cell $(n=5)$. Scale bar represents $10 \mu M$. 
To assess the 1803F-GFP system in meiocytes, we subsequently isolated male meiocyte columns from wild-type plants and from transgenic plants harboring pRPS5A::1803F:(GGGGS): $G F P$, and examined them by confocal fluorescence microscopy. Male meiocytes from transgenic plants harboring pRPS5A::1803F:(GGGGS) $: G F P$ clearly displayed GFP foci corresponding to $1803 \mathrm{~F}-\mathrm{GFP}$ fusions binding to pericentromeres (Figure 4B), while meiocytes isolated from wild-type Col-0 plants did not (Figure 4B). These observations demonstrated that the $1803 \mathrm{~F}-\mathrm{GFP}$ reporter system provides for a clear read-out for meiotic effector protein expression, and that pRPS5A is active during meiosis, which is a novel finding. To corroborate these observations, we constructed a GAL4-based two-step (2S) variant of the pRPS5A expression cassette, in which pRPS5A drives the expression of GAL4-VP16, which in turn can transactivate a flanking 4xUAS-minimal35S::1803F:( $G G G G S)_{3}: G F P$ reporter gene (p2S-RPS5A::1803F:(GGGGS) $G F P$ in short). This $2 \mathrm{~S}$ construction, which was based on an earlier published enhancer trap approach ${ }^{25,26}$, was expected to provide for an essentially similar expression pattern as in pRPS5A:: $1803 F:(G G G G S)_{3}: G F P$ reporter lines, but, due to the fact that GAL4-VP16 is a potent activator of multiple UAS-driven gene expression, would have higher overall strength. We subsequently isolated male meiocyte columns from transgenic plants harboring the two-step p2S-RPS5A:: 1803F:(GGGGS) $)_{3}: G F P$ variant, and examined them by confocal microscopy. Nuclei of meiocytes harboring p2S-RPS5A::1803F:(GGGGS) $)_{3}: G F P$ indeed displayed clear GFP foci which now had a slightly higher signal intensity (Figure 4B), and displayed less background GFP fluorescence than meiocytes from transgenic plants harboring pRPS5A:: 1803F:(GGGGS) $)_{3}: G F P$. These data showed that the $2 \mathrm{~S}$ expression cassette is also a suitable reporter for meiotic activity of promoters of interest.
We further investigated the resolution of the 1803F-GFP system by assessing the number of visible chromosomes in the nuclei of meiocytes in male meiocyte columns (Figure 4C). When examining $1803 \mathrm{~F}-\mathrm{GFP}$ foci in the surrounding somatic tissue, the number of chromosomes per cell was always ten $(2 n=10)$. This dropped to approximately five GFP foci in meiocytes of transgenic plants harboring p2S-RPS5A::1803F:(GGGGS) $)_{3}: G F P$ (Figure 4C), confirming that these cells were either haploid, or that chromocenters were in close proximity. In this case, it also has to be noted that the raw images did not require any further processing besides zooming in on nuclei. Hence, the 1803 F-GFP reporter system combined with confocal microscopy had sufficient resolution to visualize chromosomes in vivo in meiocytes using the $2 \mathrm{~S}$ expression cassette. To further corroborate this, we compared images taken from meiocytes expressing 1803F-GFP to confocal images of chromosome spreads which were prepared from flower bud tissue (Figure 4D). We found that images of DAPI-stained spreads of flower bud cells (Figure 4D) had a resolution which in terms of visibility of chromocenters was very similar to images obtained through squashing of 1803F-GFP expressing flower buds (Figure 4C), although the latter were captured in vivo without requiring any tissue fixation and staining. These observations indicated that the 1803F-GFP system had sufficient resolution to match the standard of the best available cytological images.

Visualization of the 1803F-GFP reporter system in meiocytes when driven by cloned promoter fragments

To further investigate the $1803 \mathrm{~F}-\mathrm{GFP}$ system as a read-out for meiotic effector protein expression, the cloned promoter sequences of meiotic genes (Table 2) were each ligated into binary vector pRF 1803F-GFP Kana, thereby replacing pRPS5A. Arabidopsis Col-0 plants were transformed with these fusion constructs

Table 2. Overview of confocal fluorescence microscopy on squashed flower buds of primary transformants (T1 generation) expressing 1803F-GFP fusions driven by the selected meiotically active promoters. Flower buds from on average five independent primary transformants $(n=5)$ were examined. The promoters are listed in locus ID order. Positive fluorescence signals are indicated in grey.

\begin{tabular}{|l|c|c|c|c|c|}
\hline & \multicolumn{5}{|c|}{$\begin{array}{c}\text { GFP signal in } \\
\text { GFP }\end{array}$} \\
\hline Locus ID & Promoter name & Male meiocyte column & Tetrads & Pollen & Other \\
(within flower bud)
\end{tabular}


using the floral dip method. Male meiocyte columns were then isolated from young flower buds of kanamycin-resistant primary transformants and examined by confocal fluorescence microscopy, as was done for pRPS5A. As controls, we also examined tetrads and pollen, and other tissues of flower buds which were released during the isolation of meiocytes. An overview of the results of the confocal fluorescence microscopy is provided in Table 2. Confocal microscopy images of tissues in which fluorescence foci were observed, are provided in Figure 5.
Using the 1803F-GFP system, we could show that the activity of the promoters of SPO11-1, SMC1, MS5 and p5g26622 indeed resulted in GFP foci in male meiocytes (Table 2 and Figure 5). For pSPO11-1 and p5g26622 we did not observe foci in any other tissues of the flower bud (Table 2), indicating that these promoters are indeed specifically active during meiosis. In the cases of seven other promoters ( $\mathrm{ZZYP1A}$, pSPO11-2, pNBS1, pDMC1, pMUS81, p4g40020, and p5g42530) we could not detect GFP foci in any tissue type (Table 2), while transcriptome

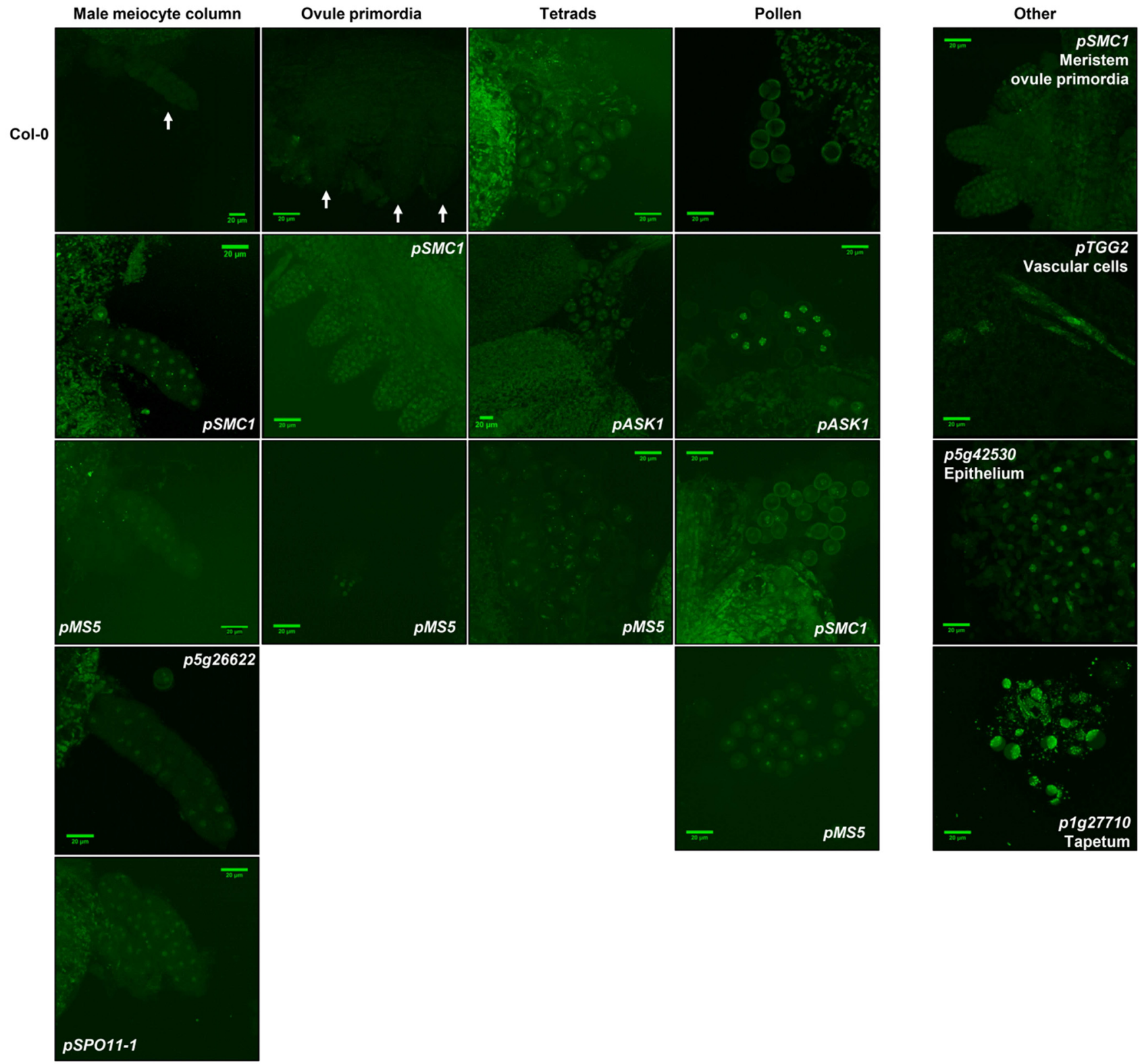

Figure 5. Confocal fluorescence microscopy on flower bud squashes of primary transformants (T1 generation) expressing 1803FGFP under control of the cloned promoters. Confocal images of male and female meiocytes (male meiocyte columns and ovule primordia, respectively) are presented, along with tetrads and pollen. For the sake of clarity of the figure only the cases where GFP signals could be observed are presented. Images of all four tissue types in Col-0 are presented as a negative control, with white arrows indicating the location in case of low background fluorescence. Scale bars represent $20 \mu \mathrm{M}$. 
data for five of these genes (ZYP1A, SPO11-2, NBS1, DMC1, and MUS81) are indicative of rather specific expression during meiosis (Table 2) ${ }^{6}$. These observations suggested that the expression levels of these genes in meiocytes are too low to be detected using the 1803F-GFP system as a reporter, which is in accordance with their low expression values in meiocytes (Table 2) $)^{6,13}$. For three promoters (p1g27710, pTGG2, and p5g42530) we did not observe expression in meiocytes, tetrads, or pollen, but noted GFP signals in other tissues in the flower bud, such as the tapetum, epithelium, and vascular cells (Table 2; Figure 5), suggesting that these promoters have very low activities in meiocytes and are not at all meiosis specific.

An overview of promoter activities described in this study which either confirm findings described in literature or are completely novel is presented in Figure 6.

\section{Establishing VirD5 expression as a novel negative selection marker for meiotic promoter activity}

As a second strategy to assess the strength and specificity of meiotic promoter activity, we assembled reporter constructs with the Agrobacterium tumefaciens virulence gene virD5. Recently, the virulence protein VirD5 was described as being cytotoxic to plant cells by binding to kinetochores through an interaction with the protein Spt4, thereby disturbing mitotic cell division and leading to cell death and aneuploidy ${ }^{19}$. Transgenic plants expressing VirD5 under control of an inducible promoter could be obtained, but these died upon induction of expression ${ }^{19}$. In the present study, we hypothesized that VirD5 could also be cytotoxic to meiotic cells, and that plants expressing VirD5 under control of a meiotic promoter would grow normally, but would show partial or full sterility due to abortion of meiosis. In that manner, VirD5 expression might act as a dominant
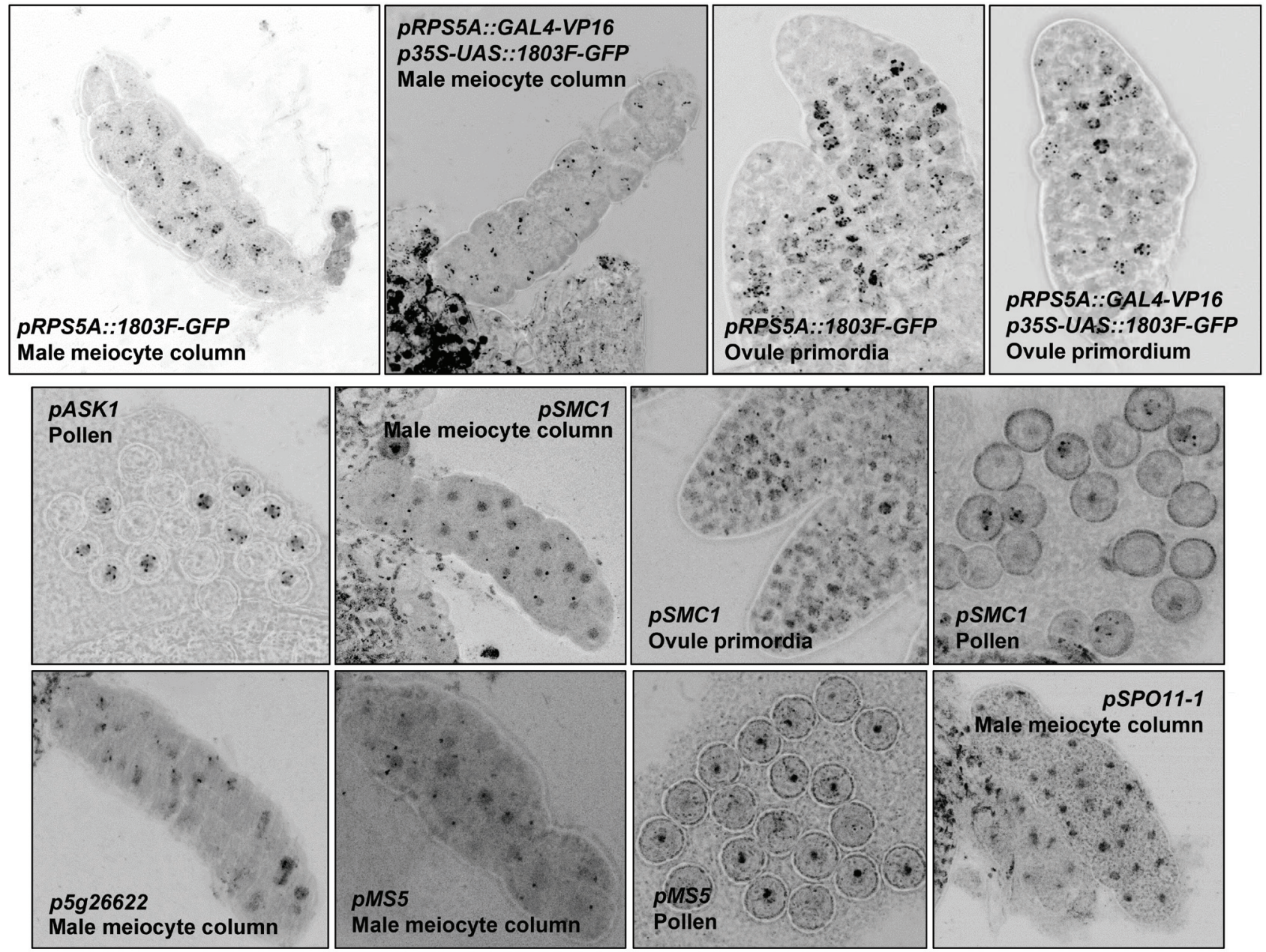

Figure 6. False color confocal microscopy images displaying the promoter activities found in this study. Presented are the most clear examples of 1803F-GFP expression in meiocytes and pollen under control pRPS5A, the GAL4-based two-step expression system (p2SRPS5A::1803F-GFP) and of the meiotically active promoters verified in this study. Fluorescence intensity and size of the confocal images was optimized to qualitatively show the nuclear foci representing 1803F-GFP fusions binding to pericentromeric regions. Therefore, no scale bars are shown. 
negative indicator of meiotic protein expression. We chose for VirD5 over other dominant negative selection marker systems because it specifically interferes with chromosome segregation and is thus likely to be particularly toxic to actively dividing cells, such as meiocytes. A schematic overview of this approach is presented in Figure 7. To establish a VirD5 based reporter system we cloned the virD5 open reading frame (ORF) from Agrobacterium tumefaciens strain LBA1 $100^{27}$ and generated fusion constructs for a selection of nine different cloned meiotic promoters of genes for which both expression data and specificity data were available ${ }^{6,13}$ (Table 1).

Assessment of meiotic promoter strength and specificity by means of VirD5 expression

Wild-type Col-0 plants were transformed with VirD5 expression constructs under control of the nine cloned promoters using the floral dip method. Viable primary transformants could be obtained at normal transformation frequencies with all of the promoters except for $p A S K 1$ and $p S M C 1$ (Table 3), which did not yield any viable primary transformants (Table 3), indicating that these promoters are not at all meiosis-specific and already active in embryos and seedlings. In case of $p A S K 1$ this is in accordance with already observed vegetative ASK1 expression patterns (Table 1), but was unexpected for $p S M C 1$, which is, more or less, a meiosis-specific promoter based on available gene expression data (Table 1). Viable, fully developed primary transformants could be obtained at high frequencies for the other seven promoters, indicating that none of them were very active in vegetative tissue.

We further noted that VirD5 expression under control of $p Z Y P 1 A$, pSPO11-1 and pSPO11-2 did not impact vegetative development and flowering, but did lead to strongly reduced fertility (Table 3). Phenotyping VirD5 expressing primary transformants
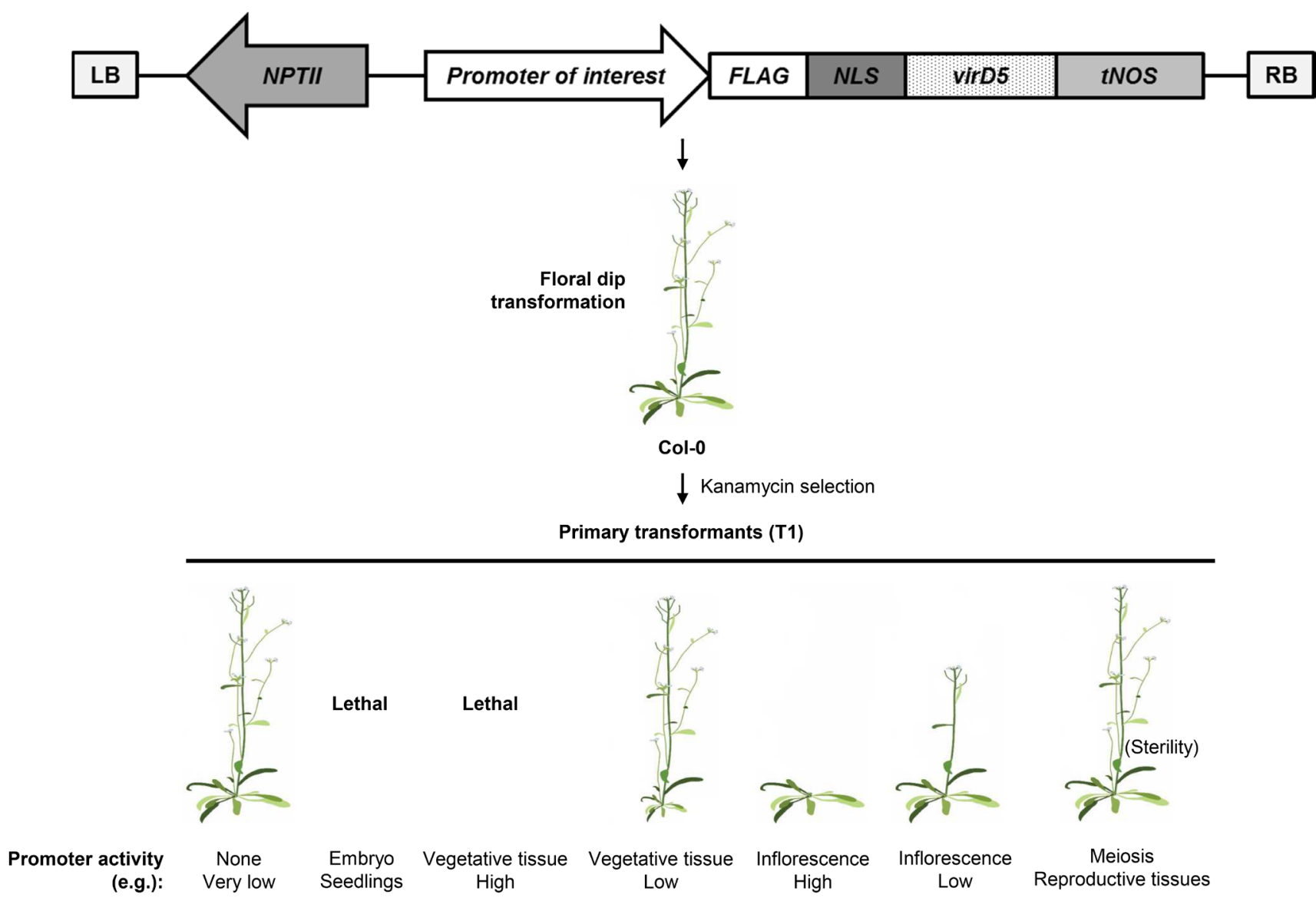

Figure 7. Screening for meiotic activity of promoters of interest using the VirD5 reporter system. A promoter of interest (Promoter of interest) is introduced into the binary vector pVirD5 Kana (e.g. as a PCR-amplified Sall-Notl fragment). The promoter then drives expression of the virD5 open reading frame with an N-terminal FLAG-tag (FLAG) and nuclear localization signal (NLS), under control of the NOS terminator sequence (tNOS). The construct is introduced into Arabidopsis plants as a T-DNA with left and right border sequences (LB and RB, respectively), through Agrobacterium tumefaciens-mediated floral dip transformation into wild-type Col-0 plants. Primary transformants (T1 generation) are selected as kanamycin-resistant individuals due to expression of the NPTII gene. Depending on the strength and tissue specificity of the activity of the promoter of interest, the viability, growth and fertility of the primary transformants can be affected. Possible examples of these effects are illustrated. In case of meiosis-specific activity, vegetative and floral development are unaffected, but the plants are sterile. 
Table 3. Overview of the output of transformations with virD5 gene constructs driven by a selection of meiotically active promoters. The promoters are listed in locus ID order.

\begin{tabular}{|c|c|c|c|c|c|c|}
\hline \multirow[b]{2}{*}{ Locus ID } & \multirow[b]{2}{*}{$\begin{array}{l}\text { Promoter } \\
\text { name }\end{array}$} & \multirow[b]{2}{*}{$\begin{array}{l}\text { Meiosis specificity } \\
\text { (meiocyte/seedling } \\
\text { expression ratio) } \\
\text { Based on Chen et al. } \\
\text { (2010) }\end{array}$} & \multicolumn{4}{|c|}{ ::virD5 } \\
\hline & & & $\begin{array}{c}\text { Transformation } \\
\text { efficiency } \\
(\%)\end{array}$ & $\begin{array}{c}\text { Number of primary } \\
\text { transformants } \\
\text { obtained } \\
\text { (from X floral dip } \\
\text { seeds) }\end{array}$ & $\begin{array}{c}\text { Viable primary } \\
\text { transformants } \\
(\%)\end{array}$ & $\begin{array}{l}\text { Primary transformants } \\
\text { with reduced fertility } \\
(\%)\end{array}$ \\
\hline At1g22260 & pZYP1A & Specific (17.0) & 0.31 & $62(20,000)$ & 98 & 21.2 \\
\hline At1g63990 & pSP011-2 & Rather specific (2.0) & 0.15 & $30(20,000)$ & 93 & 14.3 \\
\hline At1g75950 & pASK1 & Not specific (1.0) & $0.02^{*}$ & $3^{*}(20,000)$ & $0^{*}$ & N.A. \\
\hline At3g02680 & pNBS1 & Rather specific (1.6) & 0.16 & $32(20,000)$ & 94 & 6.7 \\
\hline At3g13170 & pSP011-1 & Rather specific (2.9) & 0.32 & $63(20,000)$ & 95 & 34.1 \\
\hline At3g22880 & pDMC1 & Specific (6.0) & 0.18 & $36(20,000)$ & 100 & 5.6 \\
\hline At3g54670 & pSMC1 & Rather specific (1.8) & $0.01^{*}$ & $2^{*}(20,000)$ & $0^{*}$ & N.A. \\
\hline At4g20900 & pMS5 & Not specific ${ }^{* *}$ (N.A.) & 0.16 & $32(20,000)$ & 100 & 0.0 \\
\hline \multirow[t]{2}{*}{ At4g30870 } & pMUS81 & Rather specific (4.0) & 0.20 & $39(20,000)$ & 97 & 2.6 \\
\hline & & $\begin{array}{c}\text { pRPS5A::1803F-GFP } \\
\text { (negative control) }\end{array}$ & 0.54 & $54(10,000)$ & 100 & 7.4 \\
\hline
\end{tabular}

* Primary transformants could be obtained at low frequencies, but died when transferred to soil

** Based on Yang et al. (2011)

thus provided experimental evidence that these promoters are largely inactive during vegetative development and therefore might indeed be meiosis specific. In the case of $p Z Y P 1 A$ this would be in accordance with a meiocyte/seedling expression ratio of 17.0 (Table 1 and Table 3), indicating meiosis-specific expression. Furthermore, these data indicated that both $P S P O 11-1$ and pSPO11-2 could be more meiosis-specific than might be expected based on the meiocyte/seedling expression ratios (Table 1). We decided to further analyze the effects of $p Z Y P 1 A$ and $P S P O 11-1$ in more detail, because these primary transformants were the most viable and at the same time displayed the most reduced fertility, indicating meiosis specificity.

\section{VirD5 expression under control of meiosis specific} promoters $p Z Y P 1 A$ and $p S P 011-1$

To further assess meiosis specificity of pZYP1A and pSPO111 we stained siliques of representative primary transformants with cottonblue-lactophenol to examine the quality of seed set and the viability of the embryos. Whereas siliques of control plants expressing 1803F-GFP under control of pRPS5A exhibited normal silique development with all positions in the siliques producing viable seeds (Figure 8A), siliques of transformants expressing VirD5 under control of $p Z Y P 1 A$ and $p S P O 11$ were mostly much shorter and also contained many fewer viable seeds (Figure 8A). As the flowers did not show any obvious defects, these observations indicated that VirD5 is indeed cytotoxic to meiocytes or to their precursor cells, leading to substantially reduced fertility. In the case of pSPO11-1, loss of fertility was accompanied by substantial heterogeneity in seed size among the T2 seed pool (Figure 8B). Remarkably, most small seeds still germinated and finally produced normal plants. It has to be noted, however, that even though expression of VirD5 under control of pSPO11-1 severely affected fertility, it never completely abolished seed set, indicating that PSPO11-1, even though meiosis-specific, is not a very strong promoter. As an alternative possibility, it might be that interference with meiotic chromosome segregation by VirD5 could still allow for the generation of a small fraction of balanced gametes with 5 chromosomes, just as observed for spol1-1 mutants ${ }^{28}$. To further address this, we constructed a $2 \mathrm{~S}$ expression construct (placing expression of GAL4-VP16 under control of pSPO11-1, and transactivating a flanking 4xUAS-minimal35S::virD5 reporter construct) to artificially enhance the activity of $p S P O 11-1$, as we observed for the $p 2 S-R P S 5 A$ construct (Figure 8B). Primary transformants expressing VirD5 under control of this $2 \mathrm{~S}$ construct were only slightly hampered in vegetative rosette development but were fully sterile compared to control plants (Figure 8C). This again corroborated that $p S P O 11-1$ is likely to be a very meiosisspecific promoter with at most low activity in other tissues. To further investigate the cause of the reduced fertility observed in plants harboring $p S P O 11-1$ and $p Z Y P 1 A$, we analyzed pollen production and pollen viability in five different plant lines for each construct. Staining of stage 12 flower buds ${ }^{29,30}$ showed that pollen production as well as viability were indistinguishable from wild-type plants. Hence, using the promoters mentioned, VirD5 expression did not distort the development of cells prior to the formation of pollen, neither of pollen development itself. It might have been that female gametogenesis was partially distorted, but further experimental exploration of this possibility has not yet been investigated.

Complete raw imaging data are available on Figshare ${ }^{31}$. 

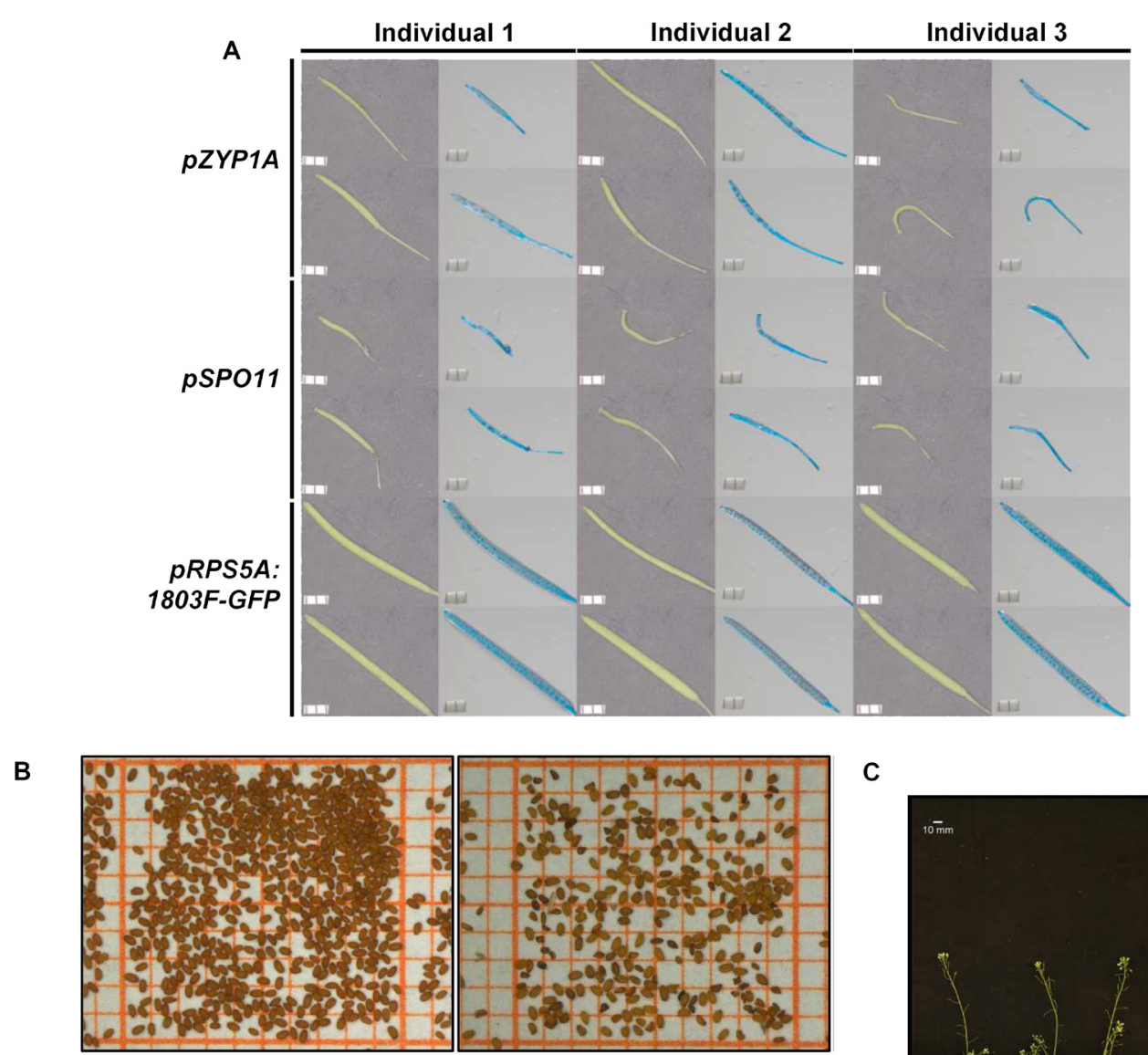

pRPS5A:1803F-GFP

pSPO11::virD5

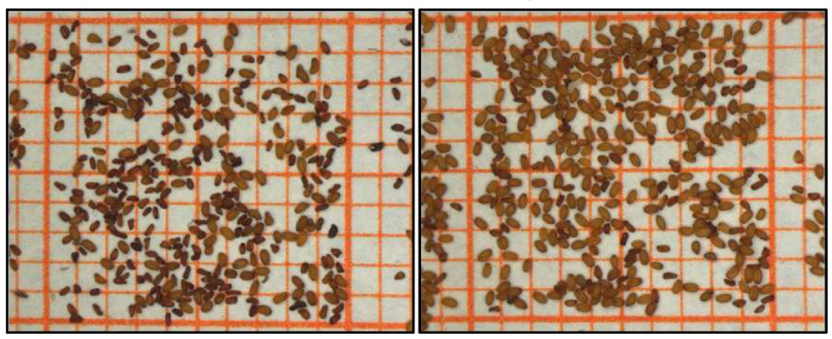

C

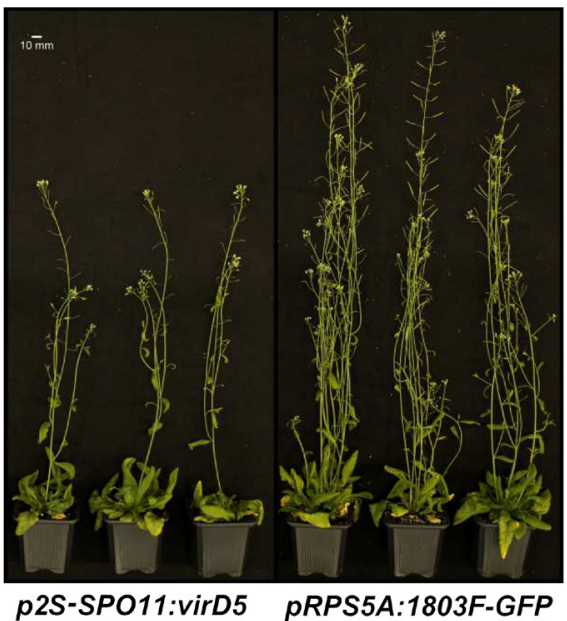

pSPO11::virD5

pSP011::virD5

Figure 8. The effects of VirD5 expression under control of the cloned promoter sequences of SP011 (pSPO11) and ASK1 (pASK1) on fertility and seed set. (A) Cotton blue staining of siliques of primary transformants expressing VirD5 under control of $p Z Y P 1 A$ and $p S P O 11$. Two stained and unstained siliques, respectively, are presented for three individual primary transformants. Siliques of primary transformants harboring the construct pRPS5A::1803F-GFP are presented as a negative control. Scale bars represent 2 mm. (B) Photos of seeds of three independent primary transformants expressing VirD5 under control of $p S P 011$. Seeds of a representative primary transformant harboring pRPS5A::1803F-GFP are presented as a negative control. The seeds were spread on grid paper, with each square representing $1 \mathrm{~mm}^{2}$. (C) Photos of primary transformants expressing VirD5 under control of the GAL4-based two-step expression system (p2S-RPS5A::1803FGFP). Primary transformants harboring the construct pRPS5A::1803F-GFP are presented as a control. Scale bar represents $10 \mathrm{~mm}$.

\section{Discussion}

Here, we have described two novel strategies to assess the suitability of portable promoter elements to drive effector protein expression in meiocytes. The first strategy, based on expression of 1803F-GFP fusions under control of promoters of interest, has proven to be a suitable method to investigate such activity in meiocytes in vivo without the requirement of tissue lysis, fixation or staining. The second strategy, based on expression of the cytotoxic Agrobacterium tumefaciens virulence protein VirD5, proved to be an additional and partly complementary tool to gather in planta cues regarding promoter strength and specificity, especially when combined with available gene expression data sets. 
The 1803F-GFP strategy allows for the relatively simple introduction of PCR-amplified promoter fragments into the binary vector $\mathrm{pRF}$ 1803F-GFP Kana. Visualization of GFP signal in meiocytes can then be performed directly in the T1 generation after floral dip transformation. In addition, an important advantage of this approach over other available approaches is that promoter activity can be studied in vivo without the requirement of disruptive procedures such as lysis, fixation or staining. Finally, the formation of GFP foci localized to the pericentromeric regions of all five chromosomes allows for the discrimination of true GFP signals from autofluorescence as well as for ploidy determination. The 1803F-GFP system could also be combined with other techniques (e.g. chromosome spreading) to draw further conclusions with respect to expression levels or cytology. Of course, just as for any other reporter of gene expression, claims regarding promoter specificity should be interpreted with care. GFP signals in meiocytes could in theory also be due to inheritance of $1803 \mathrm{~F}-\mathrm{GFP}$ transcripts or proteins from progenitor cells.

In the present study we could not detect GFP foci when $1803 \mathrm{~F}$ GFP expression was driven by the promoters of ZYP1A, SPO112, NBS1, DMC1 and MUS81 (Table 2). These genes are by their function known to be expressed during early prophase I of meiosis $I^{1}$, but their mRNA levels are relatively low in meiocytes (Table 1). It could therefore be that low and subphase-specific promoter activity is difficult to detect with the $1803 \mathrm{~F}-\mathrm{GFP}$ system. In addition, it is known that meiocytes progress through prophase I of meiosis I relatively quickly ${ }^{32}$, making the isolation of meiocytes columns which are in a specific subphase of prophase I a very challenging task. The usefulness of the 1803F-GFP reporter system is therefore to some extent limited by the ability to isolate meiocytes in the correct meiotic subphase of interest.

The VirD5 reporter system in principle allows for the screening of promoter elements with tissue-type specific activities without the requirement of any a priori knowledge. Valuable biological cues regarding promoter strength and specificity can already be gathered by phenotyping primary transformants expressing VirD5 under control of a promoter element. In addition, when gene expression data sets are available, the VirD5 reporter system can be used to further verify promoter activity in a tissue type of interest, or to confirm that expression patterns are indeed limited to a specific tissue type. It must be realized that expression of VirD5 in cells that support reproductive tissues could also lead to sterility. Further investigation of promoter activity might thus be required when VirD5 expression is observed to trigger sterility.

The strategy of using VirD5 expression as a dominant negative indicator for cell ablation offers an interesting alternative to the use of other negative selection markers, because it specifically interferes with chromosome segregation ${ }^{19}$. Its expression is therefore only detrimental to dividing cells, and less likely to be toxic to other types of cells when expressed at low levels. By comparison, the protein synthesis inhibiting diphtheria toxin from the pathogenic bacterium Corynebacterium diphteriae, which is widely used as a potent negative selection marker (e.g. 33-35), is highly toxic to all cells undergoing mRNA translation and therefore lethal to every cell type, also when expressed at low levels. The VirD5 strategy might therefore offer an interesting alternative by excluding lethality due to biologically insignificant levels of transgene expression.

\section{Conclusions}

Altogether the data presented here demonstrated that effector protein expression in meiocytes can be visualized in vivo using the 1803F-GFP reporter system, which facilitates the assessment of meiotic promoter activity. The promoters investigated in this study were selected primarily based on published studies on male meiosis ${ }^{6,13}$, but for future studies the activity and strength of any promoter could in principle be assessed in meiocytes (or other tissue types of interest) using the 1803F-GFP reporter system. In addition, we showed that expression of the Agrobacterium tumefaciens virulence protein VirD5 can be used as a novel negative selection marker and can also provide for experimental cues on tissue specificity and strength of cloned promoter fragments of interest. Combining the 1803F-GFP and VirD5 reporter systems with available gene expression data sets could greatly facilitate the identification of portable promoter elements with desired tissue specificity and/or strength.

\section{Methods}

Plant material and growth conditions

All plants in this study were grown on soil in a climate-controlled growth chamber at a constant temperature of $20^{\circ} \mathrm{C}, 70 \%$ relative humidity, a light intensity of approximately $150 \mu \mathrm{mol} \mathrm{m} \mathrm{m}^{-2} \mathrm{~s}^{-1}$ of photosynthetically active radiation from SPAR tubes, and at a $16 \mathrm{~h}$ photoperiod. All transgenic plants were generated in the Col-0 background.

\section{Molecular cloning of promoter sequences}

The selected promoter sequences (Table 1) were PCR-amplified from genomic DNA of Col-0 plants isolated with the CTAB protocol $^{36}$, using nested PCR with a gene-specific forward primer (Table 4) and four overlapping reverse primers (three genespecific and one universal reverse primer; Table 4). The PCR conditions are listed in Table 5. Where possible, PCR primers were designed to amplify the full genomic region between the ATG start codon of the gene of interest and the first or last exon of the adjacent gene (depending on the ORF of that gene lying on the positive or negative strand). Due to a lack of suitable primer target sites, the cloned intergenic regions were $300 \mathrm{bp}$ shorter for At1g75950 (ASK1) and 170 bp shorter for At3g54670 (SMC1). For At1g22260 (ZYP1A), the cloned 2102 bp fragment reached up to At1g22275 (ZYP1B) and included the complete At1g22270 (SMO2) sequence. The DMC1 gene (At3g22880) is separated by $7280 \mathrm{bp}$ from the neighboring At3g22886 (MIR167A) sequence. In this case, we amplified a $3123 \mathrm{bp}$ upstream sequence which includes an 1881 bp LIMPET1 transposable element. The amplified sequence is $177 \mathrm{bp}$ longer than the reportedly active Col-0 sequence used in a previous study ${ }^{7}$ but might be effectively shorter than the $\sim 3200$ bp upstream sequence from the Landsberg erecta ecotype which does not contain the LIMPET1 element ${ }^{37}$. The forward primer and the universal 
Table 4. Primers used to PCR-amplify the promoter sequences of the selected meiotic genes from genomic DNA of Col-0. The genes are listed in locus ID order.

\begin{tabular}{|c|c|c|c|}
\hline Locus ID & Primer name & Oligo sequence (5'-3') & $\begin{array}{l}\text { Restriction site } \\
\text { underlined }\end{array}$ \\
\hline All & Universal REV & AGCGGCCGCTTATCGTCGTCGTCCTTGTAGTC & Notl \\
\hline \multirow[t]{4}{*}{ At1g22260 } & FW & GGTCGACTCTAGATCGGAGATCGAGAAAGTAAGCTACAAAAATG & Sall \\
\hline & REV1 & CGGAGATAAAATTGAAATGAAAAAGATGACGAAATCGATCTATCG & \\
\hline & REV2 & AGTCGGCCATCTCTAGATCGGAGATAAAATTGAAATGAAAAAGATGACG & \\
\hline & REV3 & CTTATCGTCGTCGTCCTTGTAGTCGGCCATCTCTAGATCG & \\
\hline \multirow[t]{4}{*}{ At1g27710 } & FW & GGTCGACTTGAGCAGATGAAAAAAAACAAACTAATTTCCTAATCCTTGGAAG & Sall \\
\hline & REV1 & TGCTTAGTGACACAATTTGTTTGCTTAGAATCTGAAAAAGGAAGTA & \\
\hline & REV2 & GTCGGCCATGATGGCTGCTTAGTGACACAATTTGTTTGCTTAGA & \\
\hline & REV3 & CTTATCGTCGTCGTCCTTGTAGTCGGCCATGATGGCTGCTT & \\
\hline \multirow[t]{4}{*}{ At1g63990 } & $\mathrm{FW}$ & GGTCGACGCTTTCACTATCTTGCTAGATCTCTCTCTCTCTCTCTT & Sall \\
\hline & REV1 & CCGATTCCGCTTTTTTTGAAATTTTGATTTGAATTTGATTGAGAG & \\
\hline & REV2 & GTCGGCCATTTTGAGATTTTTTTTTCCGATTCCGCTTTTTTGAAATTTTGA & \\
\hline & REV3 & CTTATCGTCGTCGTCCTTGTAGTCGGCCATTTTGAGATTTTTTTTCC & \\
\hline \multirow[t]{4}{*}{ At1g75950 } & FW & GGTCGACAGATGGTCGTATGATCCAAATCTCTAACTATTTTAAAATGTG & Sall \\
\hline & REV1 & TGGAAACGAAGAGAGAAGAGAAAGATTTTAGATTTGGGAGATTTG & \\
\hline & REV2 & CTTATCGTCGTCGTCCTTGTAGTCGGCCATGGTTATGGA & \\
\hline & REV3 & CTTATCGTCGTCGTCCTTGTAGTCGGCCATGGTTATGGA & \\
\hline \multirow[t]{4}{*}{ At3g02680 } & FW & GGTCGACAGGTGTTTAGTGCTTGTTTATATAGGCGCCTATATTTAG & Sall \\
\hline & REV1 & CTTCGCTCCAAGAAATCCTTGTTCGAAAGGG & \\
\hline & REV2 & TAGTCGGCCATTTTGCTTCGCTCCAAGAAATCCTTGTTC & \\
\hline & REV3 & CTTATCGTCGTCGTCCTTGTAGTCGGCCATTTTGCTTCG & \\
\hline \multirow[t]{4}{*}{ At3g13170 } & FW & GCTCGAGCTTCACCAAACTTGACTAAGTATGAGACCTCT & Xhol \\
\hline & REV1 & GTTTCAAAACTGAAAAATGCAATGGTCGACGAATTTTTGTAG & \\
\hline & REV2 & TAGTCGGCCATCTCTTTCGAGTTTCAAAACTGAAAAATGCAATGGTC & \\
\hline & REV3 & CTTATCGTCGTCGTCCTTGTAGTCGGCCATCTCTTTCGAG & \\
\hline \multirow[t]{4}{*}{ At3g22880 } & FW & GGTCGACCACTTCTTTTGATATAGGGAGATTCGTTGAGCA & Sall \\
\hline & REV1 & CGCTCTAAGAGTCTCTAAGCTTGGAAGAGTGAG & \\
\hline & REV2 & TGTAGTCGGCCATTTTCTCGCTCTAAGAGTCTCTAAGCTTGGA & \\
\hline & REV3 & CTTATCGTCGTCGTCCTTGTAGTCGGCCATTTTCTCG & \\
\hline \multirow[t]{4}{*}{ At3g54670 } & FW & GGTCGACGCTACCAAACTGACAATAACTCCAC & Sall \\
\hline & REV1 & TGGGGGAGAGATCTCGAGTTTGGTTTCAGAG & \\
\hline & REV2 & TGTAGTCGGCCATGATTGGGGGAGAGATCTCGAGTT & \\
\hline & REV3 & CTTATCGTCGTCGTCCTTGTAGTCGGCCATGATTGGG & \\
\hline \multirow[t]{4}{*}{ At4g20900 } & FW & GGTCGACTAGGGCATGGGTTTAGATGTGAAGTGAAGA & Sall \\
\hline & REV1 & TCGATTCTCTCTGTCAATTTACTCAGATAAAGTTCGAGAAAGC & \\
\hline & REV2 & GTCGGCCATTTTCTTTTTCGATTCTCTCTGTCAATTTACTCAGAT & \\
\hline & REV3 & CTTATCGTCGTCGTCCTTGTAGTCGGCCATTTTCTTTTTCGATT & \\
\hline \multirow[t]{3}{*}{ At4g30870 } & FW & GGTCGACTGTTTGGTTGTATCTTGGGGAGCA & Sall \\
\hline & REV1 & CACTACCCACTCCAAATAGTTTCAATTTATCAAGCG & \\
\hline & REV2 & TGTAGTCGGCCATCACTACCCACTCCAAATAGTTTCAAT & \\
\hline
\end{tabular}




\begin{tabular}{|c|c|c|c|}
\hline Locus ID & Primer name & Oligo sequence (5'-3') & $\begin{array}{l}\text { Restriction site } \\
\text { underlined }\end{array}$ \\
\hline & REV3 & CTTATCGTCGTCGTCCTTGTAGTCGGCCATCACTACC & \\
\hline \multirow[t]{4}{*}{ At4g40020 } & FW & GTCGACTGTTACTGTCTCCGCGATCTGATTTTACGA & Sall \\
\hline & REV1 & TCGGCCATAGATGATAGAATGTTTTTTTATTCAGCGT & \\
\hline & REV2 & CCTTGTAGTCGGCCATAGATGATAGAATGTTTTTTATTCAGCGT & \\
\hline & REV3 & CTTATCGTCGTCGTCCTTGTAGTCGGCCATAGATGA & \\
\hline \multirow[t]{4}{*}{ At5g25980 } & FW & GGTCGACCCAAACTTTTGAGTTCTTGAGTAGGTAACGTCAC & Sall \\
\hline & REV1 & CTTGTGCCAATCTAGGGTTTATATAGCCTTTGTAAAGAAGAGT & \\
\hline & REV2 & GTCGGCCATGGAAGCCTTGTGCCAATCTAGGGTTTATATAGC & \\
\hline & REV3 & CTTATCGTCGTCGTCCTTGTAGTCGGCCATGGAAGCCT & \\
\hline \multirow[t]{4}{*}{ At5g26622 } & FW & GGTCGACCATTGATGGACATTCTCTGTAGTTATTGAGCACAAG & Sall \\
\hline & REV1 & AACTTAAAGCTAAGAGAGGACAACAGACGCTTCAC & \\
\hline & REV2 & GTAGTCGGCCATGAATCGACACAACTTAAAGCTAAGAGAGGACAACAG & \\
\hline & REV3 & CTTATCGTCGTCGTCCTTGTAGTCGGCCATGAATCGACAC & \\
\hline \multirow[t]{4}{*}{ At5g42530 } & FW & GGTCGACCTCTGGATAAGCCATCTGTAGAACGACG & Sall \\
\hline & REV1 & ATTTTGCTTATCAGTGCCACTCATGCTTATGCC & \\
\hline & REV2 & TAGTCGGCCATCTTAATATTCCCTCTTATTTTGCTTATCAGTGCCACTCA & \\
\hline & REV3 & CTTATCGTCGTCGTCCTTGTAGTCGGCCATCTTAATATTCCCTCT & \\
\hline
\end{tabular}

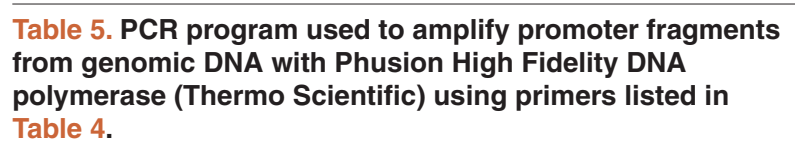

\begin{tabular}{|c|c|c|c|}
\hline Step & Temperature $\left({ }^{\circ} \mathbf{C}\right)$ & Time (min:s) & Cycles \\
\hline Initial denaturation & 98 & $3: 00$ & $1 \mathrm{x}$ \\
\hline Denaturation & 98 & $0: 10$ & $2-4 \mathrm{x}$ \\
\hline Annealing & 68 & $0: 20$ & \\
\hline Extension & 72 & $1: 30$ & \\
\hline Denaturation & 98 & $0: 10$ & $39 x$ \\
\hline Extension & 72 & $1: 30$ & \\
\hline Final extension & 72 & $5: 00$ & $1 \mathrm{x}$ \\
\hline
\end{tabular}

reverse primer were added to the PCR mix at the final concentration advised by the manufacturer of Phusion High-Fidelity DNA Polymerase (Thermo Fisher Scientific). Reverse primers 3, 2 , and 1 were added to $1 / 5,1 / 10$, and $1 / 10$ of the final concentration advised by the manufacturer, respectively. In this manner, relatively large PCR products of the promoter sequences fused to a FLAG tag and a nuclear localization signal (NLS) at the 3' end, flanked by SalI and NotI restriction sites (5' and 3' ends, respectively, except for the promoter sequence of SPO11-1, which was flanked by XhoI and NotI sites) could be generated in a single PCR reaction. Although the FLAG tag did not serve a direct purpose in the present study, it can be useful for immunological purposes such as pulldown of meiocyte proteins interacting with FLAG-tagged proteins of interest. The PCR products were ligated into the pJET Blunt cloning vector using the CloneJet PCR Cloning Kit (Thermo Fisher Scientific) and their identity was confirmed by Sanger sequencing (Macrogen Europe).

Construction of pRF 1803F:(GGGGS) :GFP Kana

For the construction of pRF 1803F:(GGGGS):GFP Kana, the previously published binary vector pRF EAR Kana ${ }^{16}$ was taken as a cloning scaffold. The oligo DNA fragments 'Kpn EAR Sac FW' and 'Kpn EAR Sac RV' (Table 6) were annealed and ligated into KpnI and $S a c \mathrm{I}$ digested pRF EAR Kana, thereby removing the $K p n I$ site and introducing (among others) XhoI and SpeI sites into the backbone. Subsequently, oligo DNA sequences encoding the (GGGGS) ${ }_{3}$ flexible linker (GGGGS 


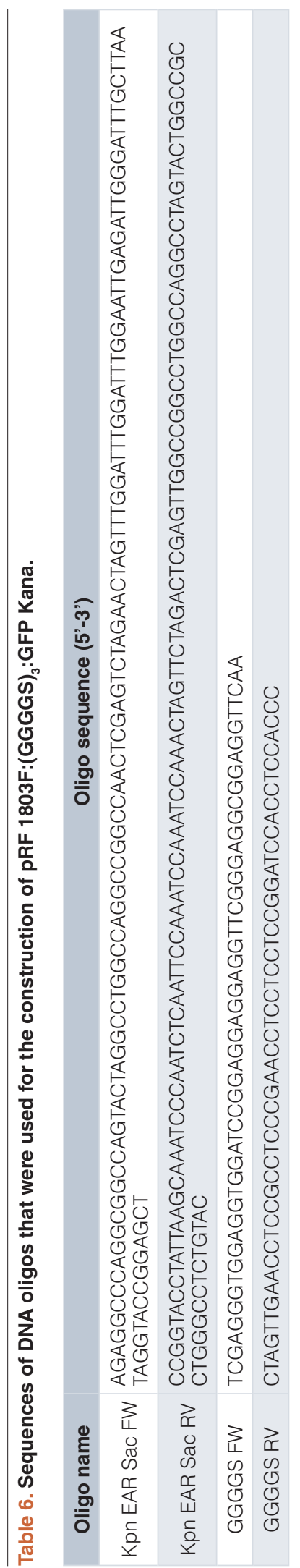


FW and RV; Table 6) were annealed and ligated into the backbone between the XhoI and SpeI sites, yielding the plasmid pRF (GGGGS) ${ }_{3}$ Kana. The sequence encoding eGFP was PCR amplified from the plasmid pART $7^{38}$, and subsequently ligated between the former $K p n I$ site and the SacI site, yielding the plasmid pRF (GGGGS):GFP Kana. The 1803F encoding sequence $^{20,22}$ was ligated as a SfiI fragment into SfiI digested pRF (GGGGS): GFP Kana, finally yielding the binary vector pRF 1803F:(GGGGS) :GFP Kana.

Construction of binary vectors with meiotic promoters The cloned promoter sequences were digested from pJET with SalI and NotI (or XhoI and NotI in the case of pSPO11-1), and were ligated into SalI and NotI digested pRF 1803F:GFP Kana (containing $p R P S 5 A)^{20}$. For the construction of a GAL4based two-step (" $2 S$ ") expression system ( $p R P S 5 A$ or any other promoter of choice driving the expression of GAL4-VP16, which transactivates a flanking 4xUAS-minimal35S::1803F:GFP reporter construct), a $1471 \mathrm{bp}$ DNA sequence with key elements essentially as described previously ${ }^{25,26}$, but directly compatible with our vector systems was synthesized (BaseClear, Leiden, The Netherlands; Figure 9), and subsequently ligated as an EagI fragment into pRF 1803F:GFP Kana predigested with NotI.
Cloning the virD5 ORF in binary vectors carrying different promoters

For the amplification of the virD5 ORF, genomic DNA of Agrobacterium tumefaciens strain LBA1100 harboring the disarmed octopine-type Ti plasmid pTiB6 ${ }^{27}$ was extracted using the DNeasy Blood \& Tissue Kit (QIAGEN) according to the manufacturer's instructions, except that lysis of the cells was performed in TES $(10 \mathrm{mM}$ Tris $\mathrm{HCl} \mathrm{pH} 8.0,50 \mathrm{mM}$ EDTA, $50 \mathrm{mM}$ $\mathrm{NaCl}$ ) containing $400 \mu \mathrm{g} / \mathrm{ml}$ lysozyme. The virD5 ORF followed by its TGA stop codon and 54 bp of its downstream non-coding sequence was PCR amplified from the genomic DNA of LBA1100 using the forward and reverse primer combination VirD5 NotI FW (5'- ATTAGCGGCCGCTGACAGGAAAGTCGAAAGTTCAC-3'; NotI site underlined) and VirD5 SpeI RV (5'- TAATACTAGTTATCAACCAGCGATCGATGC-3'; SpeI site underlined). The resulting PCR product was ligated into the pJET Blunt cloning vector using the CloneJet PCR Cloning Kit (Thermo Fisher Scientific) and sequenced by Sanger sequencing (Macrogen Europe). Subsequently, the virD5 ORF was ligated as a NotI-SpeI fragment into pRF 1803F:GFP Kana derivatives described above harboring the cloned promoter sequences of MUS81, NBS1, SMC1, SPO11-1, SPO11-2 and ZYP1A, respectively. The relevant restriction sites are depicted in Figure 2.

Eagl TAATAAGCGGCCGCATAAATTGCTGTCGTCAATTGAGCAAGCTTGTGATATTTGTAGACTTAAGAAGTTGAAGTGTTCAAAGGAAAAACCT

AAATGTGCGAAATGTTTGAAAAATAACTGGGAATGTAGATATTCGCCAAAAACCAAACGAAGCCCTTTAACAAGAGCACATCTCACAGAAG

TTGAGTCAAGATTGGAGCGATTGGAACAATTATTCCTGTTGATCTTCCCAAGAGAAGACCTGGACATGATTTTGAAGATGGATTCGTTACA

AGACATTAAGGCGCTTTTGACCGGACTTTTCGTGCAGGACAACGTGAACAAAGATGCGGTAACTGACAGACTAGCTTCTGTTGAGACCGAC

ATGCCGCTTACTCTCAGACAACACAGAATATCCGCCACTTCATCAAGTGAAGAAAGTAGCAATAAAGGACAAAGACAGCTAACTGTCTCGA

CCGCACCGCCAACTGATGTGTCGCTCGGAGATGAACTGCACCTAGATGGAGAGGATGTCGCAATGGCCCACGCTGATGCGTTAGATGATTT

TGACCTCGATATGCTAGGAGATGGTGATTCTCCTGGTCCAGGATTTACGCCTCACGATTCTGCACCATACGGGGCCTTAGATATGGCGGAT

\begin{tabular}{l} 
TTCGAGTTTGAACAAATGTTCACTGACGCCCTCGGAATTGATGAATATGGTGGTTGAAGATCTAAGCTTTCGTCCGTATCATCGGTTTCGA \\
CAACGTTCGTCAAGTTCAATGCATCAGTTTCATTGCCCACACACCAGAATCCTACTAAGTTTGAGTATTATGGCATTGGAAAAGCTGTTTT \\
\hline
\end{tabular}

CTTCTATCATTTGTTCTGCTTGTAATTTACTGTGTTCTTTCAGTTTTTGTTTTCGGACATCAAAATGCAAATGGATGGATAAGAGTTAATA

AATGATATGGTCCTTTTGTTCATTCTCAAATTATTATTATCTGTTGTTTTTACTTTAATGGGTTGAATTTAAGTAAGAAAGGAACTAACAG

TGTGATATTAAGGTGCAATGTTAGACATATAAAACAGTCTTTCACCTCTCTTTGGTTATGTCTTGAATTGGTTTGTTTCTTCACTTATCTG

TGTAATCAAGTTTACTATGAGTCTATGATCAAGTAATTATGCAATCAAGTTAAGTACAGTATAGGCTTTTTGTGTCGAATGTTAATTAACA

AGGCGCGCCTCCGGGTGACAGCCCTCCGACGGGTGACAGCCCTCCGACGGGTGACAGCCCTCCGACGGGTGACAGCCCTCCGAATACGAGC pUAS

ACGGTAGCCGGGGATCTCTCGACCTCGAACGTGATCTTCGCAAGACCCTTCCTCTATATAAGGAAGTTCATTTCATTTGGAGAGGACACGC pMinimal35S

TGAAGCTACTCGACTCTAGCCTCGACACGTGTAACTAGACGCTCTGTTTCTCTCACCACAGCCATGGCTGACTACAAGGATGACGATGACA

Eagl

Start FLAG

AACGGCCGCTAATAA

Figure 9. The oligo DNA sequence (1471 bp) which was synthesized for the construction of GAL4-based two-step expression constructs. 
This procedure deleted the $1803 \mathrm{~F}$ coding domain as well as the adjacent sequence encoding the flexible linker, replacing it by the VirD5 coding region with its own TGA stop codon. Due to the presence of a SpeI site in the cloned promoter sequences of $A S K 1$ and MS5, a similar cloning strategy was followed, except that the virD5 ORF was PCR amplified using VirD5 NotI FW combined with the reverse primer VirD5 SalI RV (5'-TAATGTCGACTATCAACCAGCGATCGATGC-3'; SalI site underlined), and was ligated as a NotI-SalI fragment into NotI-XhoI digested binary vectors harboring the cloned promoter sequences of ASK1 and $M S 5$, respectively. Additionally, in these cases, the virD5 ORF was followed by its TGA stop codon and 54 bp of its downstream non-coding sequence. As a small but functionally irrelevant difference with the other constructs, the short sequence encoding the flexible linker now remained downstream of the virD5 ORF (see position of restriction sites depicted in Figure 2).

\section{Plant transformation}

Binary vectors were mobilized to the Agrobacterium tumefaciens strain AGL1 through triparental mating ${ }^{39}$. Col-0 plants were transformed with the constructs using the floral dip method ${ }^{40}$. The seed pools resulting from floral dip transformation were sterilized and stratified at $4^{\circ} \mathrm{C}$ for 3-4 days, after which they were plated on MA medium containing $35 \mu \mathrm{g} / \mathrm{ml}$ kanamycin. After one to two weeks of growth on selection medium, kanamycinresistant seedlings were transferred to soil.

\section{Dissection of flower buds, tissue preparations and confocal microscopy}

Young, unopened flower buds ${ }^{6}$ were harvested from the primary transformants harboring promoter: $1803 F-G F P$ constructs. For the isolation of male meiocyte columns, anthers were sectioned from the flower buds and placed in a drop of physiological buffer solution $(0.9 \% \mathrm{w} / \mathrm{v} \mathrm{NaCl}$, Tris buffered to $\mathrm{pH} 7.0)$ on microscope slides. Male meiocyte columns were then released by gently applying slight pressure on the cover slide, thereby also releasing tetrads and pollen into the buffer solution. Chromosome spreads of Col-0 flower tissue were performed as described previously ${ }^{41,42}$, and subsequently stained with 4',6-Diamidino2-phenylindole (DAPI). Confocal fluorescence microscopy was performed using a Zeiss LSM5 exciter (Zeiss, München, Germany) with Illuminator HXP $120 \mathrm{~V}$ and a standard photomultiplier tube (PMT) detector (maximal gain of 1250). Excitation of the tissue was performed at a wavelength of $488 \mathrm{~nm}$. Red fluorescence was collected as a negative control with a $560 \mathrm{~nm}$ long-pass filter; GFP fluorescence was collected with a $505-530 \mathrm{~nm}$ band-pass filter, with a master gain of $678 \pm 66$ (mean \pm standard deviation). Images were collected as Z-stacks with a pixel dwell time of $1.7 \pm 1.4 \mathrm{~s}$ (average \pm standard deviation). All images were collected with the same laser power.

\section{Confocal image analysis}

The Z-stack confocal images (.lsm files) were transformed into $3 \mathrm{D}$ projections using the '3D project' function of the program Fiji (Image $\mathrm{J}$ version 1.48f). Representative projections were compressed to $2 \mathrm{D}$ images, and brightness of the images was slightly enhanced using Adobe Photoshop CC 2018 (19.1.5 release) for the sake of clarity of the figures. This was done in the same way for all images. For the false color images presented in Figure 6 an overlay of the GFP channel and bright field channel was created in Adobe Photoshop, and opacity was adjusted to visualize the GFP signal inside of the tissue. The images were then merged, inverted and the intensity of black pixels was enhanced to qualitatively visualize foci of fluorescence.

\section{Analysis of seed set and seed quality}

Siliques of primary transformants harboring pRPS5A::1803FGFP, pZYP1A::virD5 and pSPO11::virD5 constructs were harvested in Carnoy's fixative (60\% ethanol, 30\% chloroform and $10 \%$ glacial acetic acid, all v/v) and stored at $4{ }^{\circ} \mathrm{C}$ until further use. Siliques were then stained with cottonblue-lactophenol/lactophenol as described previously ${ }^{43}$. The primary transformants were subsequently allowed to further set seeds (T2), which were collected. Seed quality and homogeneity were assessed by collecting images of T2 seeds on grid paper using a LeicaMZ16FA stereomicroscope (Leica, Wetzlar, Germany).

\section{Data availability}

Figshare: Two novel strategies to assess in vivo meiotic protein expression in Arabidopsis thaliana. https://doi.org/10.6084/ m9.figshare. $7808378^{31}$.

This project contains raw confocal microscopy images of meiocytes (and other flower bud tissues) isolated from transgenic plants expressing 1803F-GFP under control of the different promoter elements described in this study.

Data are available under the terms of the Creative Commons Zero "No rights reserved" data waiver (CC0 1.0 Public domain dedication).

Plant materials and bacterial strains are available from the corresponding author upon reasonable request.

\section{Grant information}

This research was supported by a partnership between Rijk Zwaan and the Dutch Technology Foundation STW (partnership project number 12427), which is the applied science division of NWO, and the Technology Programme of the Ministry of Economic Affairs, Agriculture and Innovation.

The funders had no role in study design, data collection and analysis, decision to publish, or preparation of the manuscript.

\section{Acknowledgements}

We would like to thank Dr. Yinxiang Wang and Prof. Dr. Hong Ma (State Key Laboratory of Genetic Engineering, Institute of Plant Biology, Fudan University, Shanghai, China) for personal communications about promoters of genes described in Yang et al., 2011 ${ }^{13}$. We would like to thank Prof. Dr. Hans de Jong (Wageningen UR) for helpful discussions. We would like to thank Shuai Shao for extracting genomic DNA from Agrobacterium strain LBA1100, and Dr. Reza Roushan for help with pollen analysis. 
1. Mercier R, Mézard C, Jenczewski E, et al.: The molecular biology of meiosis in plants. Annu Rev Plant Biol. 2015; 66: 297-327. PubMed Abstract | Publisher Full Text

2. Keeney S, Giroux CN, Kleckner N: Meiosis-specific DNA double-strand breaks are catalyzed by Spo11, a member of a widely conserved protein family. Cell. 1997; 88(3): 375-84.

PubMed Abstract | Publisher Full Text

3. Keeney S, Neale MJ: Initiation of meiotic recombination by formation of DNA double-strand breaks: mechanism and regulation. Biochem Soc Trans. 2006; 34(Pt 4): 523-5.

PubMed Abstract | Publisher Full Text

4. Stacey NJ, Kuromori T, Azumi Y, et al:: Arabidopsis SPO11-2 functions with SPO11-1 in meiotic recombination. Plant J. 2006; 48(2): 206-16. PubMed Abstract | Publisher Full Text

5. Osman K, Higgins JD, Sanchez-Moran E, et al:: Pathways to meiotic recombination in Arabidopsis thaliana. New Phytol. 2011; 190(3): 523-44. PubMed Abstract | Publisher Full Text

6. Chen C, Farmer AD, Langley RJ, et al:: Meiosis-specific gene discovery in plants: RNA-Seq applied to isolated Arabidopsis male meiocytes. Bmc Plant Biol. 2010; 10: 280

PubMed Abstract | Publisher Full Text | Free Full Text

7. $\mathrm{Li}$ J, Farmer AD, Lindquist IE, et al:: Characterization of a set of novel meiotically-active promoters in Arabidopsis. Bmc Plant Biol. 2012; 12: 104. PubMed Abstract | Publisher Full Text | Free Full Text

8. Lawrence EJ, Griffin $\mathrm{CH}$, Henderson IR: Modification of meiotic recombination by natural variation in plants. $J$ Exp Bot. 2017; 68(20): 5471-5483. PubMed Abstract | Publisher Full Text

9. Choi K, Reinhard C, Serra H, et al:: Recombination Rate Heterogeneity within Arabidopsis Disease Resistance Genes. PLoS Genet. 2016; 12(7): e1006179. PubMed Abstract | Publisher Full Text | Free Full Text

10. Lambing C, Franklin FC, Wang CR: Understanding and Manipulating Meiotic Recombination in Plants. Plant Physiol. 2017; 173(3): 1530-42. PubMed Abstract | Publisher Full Text | Free Full Text

11. Pelé $A$, Falque $M$, Trotoux $\mathrm{G}$, et al:: Amplifying recombination genome-wide and reshaping crossover landscapes in Brassicas. PLoS Genet. 2017; 13(5): e1006794.

PubMed Abstract | Publisher Full Text | Free Full Text

12. Fernandes JB, Séguéla-Arnaud $M$, Larchevêque $C$, et al.: Unleashing meiotic crossovers in hybrid plants. Proc Natl Acad Sci U S A. 2018; 115(10): 2431-2436. PubMed Abstract | Publisher Full Text | Free Full Text

13. Yang $\mathrm{H}, \mathrm{Lu} \mathrm{P}$, Wang $\mathrm{Y}$, et al:: The transcriptome landscape of Arabidopsis male meiocytes from high-throughput sequencing: the complexity and evolution of the meiotic process. Plant J. 2011; 65(4): 503-16.

PubMed Abstract | Publisher Full Tex

14. van Tol N, van der Zaal BJ: Artificial transcription factor-mediated regulation of gene expression. Plant Sci. 2014; 225: 58-67. PubMed Abstract | Publisher Full Text

15. Lidder P, Gutierrez RA, Salomé PA, et al: Circadian control of messenge RNA stability. Association with a sequence-specific messenger RNA decay pathway. Plant Physiol. 2005; 138(4): 2374-85. PubMed Abstract | Publisher Full Text | Free Full Text

16. Tol NV, Rolloos M, Pinas JE, et al:: Enhancement of Arabidopsis growth characteristics using genome interrogation with artificial transcription factors. PLoS One 2017; 12(3): e0174236.

PubMed Abstract | Publisher Full Text | Free Full Text

17. van Tol N, Rolloos M, Augustijn D, et al.: An Arabidopsis mutant with high operating efficiency of Photosystem II and low chlorophyll fluorescence. Sci Rep. 2017; 7(1): 3314

PubMed Abstract | Publisher Full Text | Free Full Text

18. Weijers D, Franke-van Dijk M, Vencken RJ, et al:: An Arabidopsis Minute-like phenotype caused by a semi-dominant mutation in a RIBOSOMAL PROTEIN S5 gene. Development. 2001; 128(21): 4289-99. PubMed Abstract

19. Zhang X, van Heusden GPH, Hooykaas PJJ: Virulence protein VirD5 of Agrobacterium tumefaciens binds to kinetochores in host cells via an interaction with Spt4. Proc Natl Acad Sci U S A. 2017; 114(38): 10238-43. PubMed Abstract | Publisher Full Text | Free Full Text

20. Lindhout $\mathrm{BI}$, Meckel $\mathrm{T}$, van der Zaal $\mathrm{BJ}$ : Zinc finger-mediated live cell imaging in Arabidopsis roots. Methods Mol Biol. 2010; 649: 383-98. PubMed Abstract | Publisher Full Text

21. Simon L, Voisin M, Tatout $C$, et al.: Structure and Function of Centromeric and Pericentromeric Heterochromatin in Arabidopsis thaliana. Front Plant Sci. 2015; 6: 1049 .

PubMed Abstract | Publisher Full Text | Free Full Text

22. Lindhout $\mathrm{BI}$, Fransz $\mathrm{P}$, Tessadori $\mathrm{F}$, et al.: Live cell imaging of repetitive DNA sequences via GFP-tagged polydactyl zinc finger proteins. Nucleic Acids Res.
2007; 35(16): e107

PubMed Abstract | Publisher Full Text | Free Full Text

23. Huston JS, Levinson D, Mudgett-Hunter $\mathrm{M}$, et al: Protein engineering of antibody binding sites: recovery of specific activity in an anti-digoxin single-chain $\mathrm{Fv}$ analogue produced in Escherichia coli. Proc Natl Acad Sci U S A. 1988; 85(16): 5879-83.

PubMed Abstract | Publisher Full Text | Free Full Text

24. Cook JM, Charlesworth A: Insertion of inter-domain linkers improves expression and bioactivity of Zygote arrest (Zar) fusion proteins. Protein Eng Des Sel. 2017; 30(4): 313-9.

PubMed Abstract | Publisher Full Text | Free Full Text

25. Engineer CB, Fitzsimmons KC, Schmuke JJ, et al:: Development and evaluation of a Gal4-mediated LUC/GFP/GUS enhancer trap system in Arabidopsis. Bmc Plant Biol. 2005; 5 : 9

PubMed Abstract | Publisher Full Text | Free Full Text

26. Waki T, Miyashima S, Nakanishi M, et al:: A GAL4-based targeted activation tagging system in Arabidopsis thaliana. Plant J. 2013; 73(3): 357-67. PubMed Abstract | Publisher Full Text

27. Beijersbergen A, Dulk-Ras AD, Schilperoort RA, et al.: Conjugative Transfer by the Virulence System of Agrobacterium tumefaciens. Science. 1992; 256(5061): 1324-7. PubMed Abstract | Publisher Full Text

28. Grelon M, Vezon D, Gendrot G, et al:: AtSPO11-1 is necessary for efficient meiotic recombination in plants. Embo J. 2001; 20(3): 589-600. PubMed Abstract | Publisher Full Text | Free Full Text

29. Ross, Slovin JP, Chen C: A simplified method for differential staining of aborted and non-aborted pollen grains. Int J Plant Biol. 2010; 1(2): 66-9. Publisher Full Text

30. Smyth DR, Bowman JL, Meyerowitz EM: Early flower development in Arabidopsis. Plant Cell. 1990; 2(8): 755-67. PubMed Abstract | Publisher Full Text | Free Full Text

31. van Tol N, Rolloos M, Hooykaas PJJ, et al:: Two novel strategies to assess in vivo meiotic protein expression in Arabidopsis thaliana figshare. Fileset. 2019. http://www.doi.org/10.6084/m9.figshare.7808378

32. Stronghill PE, Azimi W, Hasenkampf CA: A novel method to follow meiotic progression in Arabidopsis using confocal microscopy and 5-ethynyl-2'deoxyuridine labeling. Plant Methods. 2014; 10(1): 33. PubMed Abstract | Publisher Full Text | Free Full Text

33. Collier RJ: Understanding the mode of action of diphtheria toxin: a perspective on progress during the 20th century. Toxicon. 2001; 39(11): 1793-803. PubMed Abstract | Publisher Full Text

34. Weijers D, Van Hamburg JP, Van Rijn E, et al.: Diphtheria toxin-mediated cell ablation reveals interregional communication during Arabidopsis seed development. Plant Physiol. 2003; 133(4): 1882-92.

PubMed Abstract | Publisher Full Text | Free Full Text

35. Guerineau F, Sorensen AM, Fenby N, et al:: Temperature sensitive diphtheria toxin confers conditional male-sterility in Arabidopsis thaliana. Plant Biotechnol J. 2003; 1(1): 33-42.

PubMed Abstract | Publisher Full Text

36. Richards E, Reichardt M, Rogers S: Preparation of genomic DNA from plant tissue. Curr Protoc Mol Biol. 2001; Chapter 2:Unit2.3. PubMed Abstract | Publisher Full Text

37. Klimyuk VI, Jones JD: AtDMC1, the Arabidopsis homologue of the yeast DMC1 gene: characterization, transposon-induced allelic variation and meiosisassociated expression. Plant $J$. 1997; 11(1): 1-14 PubMed Abstract | Publisher Full Text

38. Peiter E, Maathuis FJ, Mills LN, et al.: The vacuolar $\mathrm{Ca}^{2+}$-activated channel TPC1 regulates germination and stomatal movement. Nature. 2005; 434(7031): 404-8. PubMed Abstract | Publisher Full Text

39. Lindhout BI, Pinas JE, Hooykaas PJJ, et al.: Employing libraries of zinc finger artificial transcription factors to screen for homologous recombination mutants in Arabidopsis. Plant J. 2006; 48(3): 475-83.

PubMed Abstract | Publisher Full Text

40. Clough SJ, Bent AF: Floral dip: a simplified method for Agrobacteriummediated transformation of Arabidopsis thaliana. Plant J. 1998; 16(6): 735-43. PubMed Abstract | Publisher Full Text

41. Ross KJ, Fransz P, Jones GH: A light microscopic atlas of meiosis in Arabidopsis thaliana. Chromosome Res. 1996; 4(7): 507-16. PubMed Abstract | Publisher Full Text

42. Zhong XB, Hans de Jong J, Zabel P: Preparation of tomato meiotic pachytene and mitotic metaphase chromosomes suitable for fluorescence in situ hybridization (FISH). Chromosome Res. 1996; 4(1): 24-8. PubMed Abstract | Publisher Full Text

43. Howden R, Park SK, Moore JM, et al:: Selection of T-DNA-tagged male and female gametophytic mutants by segregation distortion in Arabidopsis. Genetics. 1998; 149(2): 621-31. PubMed Abstract | Free Full Text 


\section{Open Peer Review}

\section{Current Peer Review Status: ? ? ?}

\section{Version 1}

Reviewer Report 25 July 2019

https://doi.org/10.5256/f1000research.19636.r51289

(C) 2019 Pradillo M. This is an open access peer review report distributed under the terms of the Creative Commons Attribution License, which permits unrestricted use, distribution, and reproduction in any medium, provided the original work is properly cited.

\section{Monica Pradillo}

Department of Genetics, Physiology and Microbiology, Faculty of Biology, Complutense University of Madrid, Madrid, Spain

In this method article, van Tol et al. explain two techniques to determine the activity of potential meiosis-specific promoters. They applied both to test 14 promoter sequences that were selected because they correspond to genes with a meiotic function or with high expression levels in meiocytes. The first technique is based on the use of a GFP reporter system to visually detect the chromocenters and the second involves the negative selection marker VirD5, which interacts with kinetochores and disturbs cell division. Both strategies might provide important tools for meiosis studies.

However, I agree with the other reviewers and consider some of the results presented are not completely clear.

In the first paragraph of the introduction there are some statements that need to be revised. The authors state "female meiosis takes place in carpels": it is more accurate to say that it occurs in the ovary. Later in the text "...upon completion of meiosis (male meiocytes) give rise to four haploid pollen cells": please consider that after telophase II the PMC gives rise to a tetrad of four microspores. After that, each microspore undergoes two subsequent mitotic divisions to produce one vegetative cell and two sperm cells in the mature pollen grain. At the end of the paragraph, "four haploid pollen cells that are physically attached to each other": please consider that in dicotyledonous male meiocytes cytokinesis occurs when both meiotic divisions are finished. Do the authors refer to the fact that cytokinesis has not yet taken place at the end of meiosis, and hence the physical connection?

The interpretation of the "meiocytes" shown in Figure 4 based on a smaller number of chromocentres is not correct, I agree with the other reviewers on this. The authors should consider that the nuclei of most cells exhibit a chromocenter pattern ranging from 4 to 10 (mean $\square$ 8) (Fransz et al., 2002'; Del Prete et al., 2014²). The comment in the text about Figure 4C: "confirming that these cells were either haploid, or that chromocenters were in close proximity" 
should be more specific, as the authors should know whether the images correspond to meiocytes in the first or second meiotic division.

In general, there is no appropriate quantification for the results about the GFP patterns displayed by the different promoters. Five plants (according to the caption in Table 2) have been analyzed. Did they present the same phenotype? Some variability would be expected because it is possible that more than one transgene is introduced during the transformation with Agrobacterium, plants are analyzed in heterozygous condition (T1), and transgenes have been introduced in different regions (with a different epigenetic regulation) of the genome.

The way of presenting the images in Figure 5 is quite confusing. In addition to taking into account the cell type, images should be grouped considering the genetic backgrounds to which they belong.

Regarding the strategy based on VirD5 expression, the "unexpected" result for pSMC1 is actually logical, since SMC1 is indispensable for sister chromatid cohesion, chromosome condensation and DNA repair, not only in meiotic cells (Lam et al., 2005³).

Seed quantification in siliques of transformants expressing VirD5 under control of pZYP1A and pSPO11 is necessary. In addition, a cytological analysis would be useful to determine the effect of the presence of VirD5 on meiotic chromosome segregation. As the authors state "interference with meiotic chromosome segregation by VirD5 could still allow for the generation of a small fraction of balanced gametes with 5 chromosomes". This could easily be confirmed with a simple cytological analysis. Aneuploidies (which are tolerated in Arabidopsis) could be the cause of the different size of the seeds in transformants expressing VirD5 under control of pSPO11. Was this difference in seed size observed in the case of pZYP1A?

In conclusion, the results of the two strategies are only coincident for only one of the 14 promoters analyzed ( $p S P 011-1$ ). Using the 1803F-GFP system, the activity of $p S P 011-1$ resulted in GFP foci in male meiocytes and VirD5 expression under control of this promoter did not affect vegetative development, but produced a reduction in the seed set. In summary, the strategies presented in this paper could be interesting in determining the meiotic activity of the promoters. However, it would be necessary to improve the experimentation associated with more detailed cytological observations, proper analyses and quantitative analyses of the different observed parameters (GFP foci, seed set content) in several plants. Nevertheless, these methodologies should be combined with information about tissue-specific expression levels and functional analyses of the genes tested.

\section{References}

1. Fransz $\mathrm{P}$, De Jong JH, Lysak M, Castiglione MR, et al.: Interphase chromosomes in Arabidopsis are organized as well defined chromocenters from which euchromatin loops emanate.Proc Natl Acad Sci U S A. 2002; 99 (22): 14584-9 PubMed Abstract | Publisher Full Text

2. Del Prete S, Arpón J, Sakai K, Andrey P, et al.: Nuclear architecture and chromatin dynamics in interphase nuclei of Arabidopsis thaliana.Cytogenet Genome Res. 2014; 143 (1-3): 28-50 PubMed Abstract | Publisher Full Text

3. Lam WS, Yang X, Makaroff CA: Characterization of Arabidopsis thaliana SMC1 and SMC3: evidence that AtSMC3 may function beyond chromosome cohesion.J Cell Sci. 2005; 118 (Pt 14): 3037-48 PubMed Abstract | Publisher Full Text 
Is the rationale for developing the new method (or application) clearly explained?

Yes

Is the description of the method technically sound?

Partly

Are sufficient details provided to allow replication of the method development and its use by others?

Partly

If any results are presented, are all the source data underlying the results available to ensure full reproducibility?

Partly

Are the conclusions about the method and its performance adequately supported by the findings presented in the article?

Partly

Competing Interests: No competing interests were disclosed.

Reviewer Expertise: Meiosis, Arabidopsis, cytogenetics, Homologous Recombination

I confirm that I have read this submission and believe that I have an appropriate level of expertise to confirm that it is of an acceptable scientific standard, however I have significant reservations, as outlined above.

Reviewer Report 11 June 2019

https://doi.org/10.5256/f1000research.19636.r48966

(C) 2019 Mézard C et al. This is an open access peer review report distributed under the terms of the Creative Commons Attribution License, which permits unrestricted use, distribution, and reproduction in any medium, provided the original work is properly cited.

Christine Mézard

Jean-Pierre Bourgin Institute (IJPB), INRA, AgroParisTech, CNRS, University of Paris-Saclay, Versailles, France

Laurence Cromer

Jean-Pierre Bourgin Institute (IJPB), INRA, AgroParisTech, CNRS, University of Paris-Saclay, Versailles, France

In this paper, van Tol and co-authors present a method to test the specificity of promoters to be expressed during meiosis with two different methods. Both are based on published transcriptomic data. Promoters supposed to be expressed in meiosis are used in two different experimental systems. One aims to address GFP at centromeres of meiotic cells/. The other is 
based on the expression of an Agrobacterium toxic protein VirD5 that should kill plant cells if expressed during plant development and renders plant sterile if it is only expressed during gametogenesis. In principle, both strategies are very interesting. However, experiments need more controls to obtain any conclusions.

\section{Is the rationale for developing the new method (or application) clearly explained?}

The authors could also mention that the need of meiotic specific promoters is a prerequisite to (i) study the function of genes that are essential to cell cycle genes (ii) to inactivate some genes by RNAi or other methods that are ubiquitously expressed but essential to meiosis (iii) to overexpress genes selectively during meiosis....

\section{Is the description of the method technically sound?}

There is just one detail. The cloning is supposed to remove the FLAG based on Figure 2 because the Sal1 and Not 1 sites are on each side of the FLAG. Hovewer, on Figure 1 the FLAG is kept after the cloning of the promoters

\section{Are sufficient details provided to allow replication of the method development and its use by others? If any results are presented, are all the source data underlying the results available to ensure full reproducibility?}

In general, cytological experiments suffer of a lack of appropriate controls.

As mentioned by the other reviewer, RFP cannot be used as a control in Figure 4B. Where are the scale bars in all the figures ? It is known that GFP loses its fluorescence in meiotic columns after a few minutes. Details are needed to be sure that control cells and tested cells are visualized in the same conditions. The absence of fluorescence does not mean that the construct is not expressed. It could be expressed for a short period of time. It is very important to visualized meiotic stages by adding either DAPI or propidium iodide. Another method would be to fix the cells and make spreads to be sure of the meiotic stage. In Figure 4C, the absence of DNA staining makes impossible to determine the stage of meiosis. And the assumption of having 5 dots in a meiocytes is wrong. There are stages in which meiocytes have 10 dots, others where thy have 5 dots and they are not haploid (Armstrong et al, JCS, $2001^{1}$ ). In Figure 4D, it is difficult to know which cells are shown. They are no meiotic spreads for sure. Moreover, with the pictures provided it is almost impossible to count the dots. Again in Figure 5, it is always very difficult to determine the stages of meiotic cells.

For the VIr5 experiments, we fully agree with the first reviewer, the sterility should be quantified by counting seed sets.

For the conclusions, when expression is not detected in any cell types, the absence of expression cannot be relied to the weakness of the promoters. The first control would be to be sure that the fragment containing the promoter is functional. For that, complementation would be the best way to be sure of the functionality of the promoter. One of the best example is DMC1 promoter which has been used several times to express different constructs (example in Yang et al, Plant Physiol, $2008^{2}$ ). The lack of expression could mean that the authors have missed the stage of expression and the same explanation could be given for other promoters. As the meiotic stages are not mentioned in this study, it is hard to know if meiosis has been fully explored.

Finally, as mentioned by the other reviewer, SMC1 is known to be expressed outside meiosis (Schubert et al., 2009³). This ways that transcriptomic data on meiocytes should be used with precautions.

\section{References}


1. Armstrong SJ, Franklin FC, Jones GH: Nucleolus-associated telomere clustering and pairing precede meiotic chromosome synapsis in Arabidopsis thaliana.J Cell Sci. 2001; 114 (Pt 23): 4207-17 PubMed Abstract

2. Yang $X$, Boateng KA, Strittmatter L, Burgess $R$, et al.: Arabidopsis separase functions beyond the removal of sister chromatid cohesion during meiosis.Plant Physiol. 2009; 151 (1): 323-33 PubMed Abstract | Publisher Full Text

3. Schubert V, Weissleder A, Ali H, Fuchs J, et al.: Cohesin gene defects may impair sister chromatid alignment and genome stability in Arabidopsis thaliana.Chromosoma. 2009; 118 (5): 591-605 PubMed Abstract | Publisher Full Text

Is the rationale for developing the new method (or application) clearly explained? Partly

Is the description of the method technically sound? Partly

Are sufficient details provided to allow replication of the method development and its use by others?

No

If any results are presented, are all the source data underlying the results available to ensure full reproducibility?

No

Are the conclusions about the method and its performance adequately supported by the findings presented in the article?

No

Competing Interests: No competing interests were disclosed.

Reviewer Expertise: Meiosis, Recombination, molecular genetics

We confirm that we have read this submission and believe that we have an appropriate level of expertise to confirm that it is of an acceptable scientific standard, however we have significant reservations, as outlined above.

Reviewer Report 20 May 2019

https://doi.org/10.5256/f1000research.19636.r48670

(c) 2019 Lambing C. This is an open access peer review report distributed under the terms of the Creative Commons Attribution License, which permits unrestricted use, distribution, and reproduction in any medium, provided the original work is properly cited.

Christophe Lambing 
Department of Plant Sciences, University of Cambridge, Cambridge, UK

The work from Niels van Tol et al. presents two strategies to assess promoter activity in Arabidopsis meiosis. The identification of promoters with expression specific to meiosis is of interest to the field. However, some limitations in the techniques used and in the experimental designs impaired the conclusions drawn by the authors.

Specific comments:

Page 7, Figure 4B: What is the rational to use RFP signal as control of autofluorescence for the GFP signal? These two signals have different excitation and emission wavelengths and the RFP signal will not provide any information on how much autofluorescence passing through the GFP filter is detected. A wild type plant without GFP protein is the best control for GFP autofluorescence.

Page 7, Figure 4A and 4B: It is unclear to me whether the cells labelled with GFP are meiocytes or not. It is also unclear at what stage of meiosis the cells are. It is important to use a chromatin dye here, e.g. DAPI. - see below for more comments on this

Page 7, Figure 4C: It is not apparent that we have cells with 10 and 5 chromocenters. It seems to me that there is a range of chromocenters from 3 to 10 - this would support the idea that the number of chromocenters doesn't necessary reflect the ploidy content but rather reflects specific stages in the cell cycle.

Page 7, Figure 4D: On the 2 zoom-in images $(2 n=10$ and $n=5)$, it seems to me that none of the two cells presented are meiocytes.

Page 8 - "this dropped to approximately five GFP foci in meiocytes" - I don't understand the idea that cells with less chromocenters are meiocytes. The interest of using this technique is to test for promoter activity in meiocytes. However, the authors have not fully demonstrated that they can identify meiocytes in their assay.

The authors seem to suggest that the number of chromocenters could help differentiate between meiocytes and somatic cells but the authors are not referring to any paper to support their claim. The authors then suggest that a cell with fewer than 10 chromocenters is either "haploid or that chromocenters were in close proximity". The authors didn't comment on the latter possibility and its implication with meiosis, which makes their explanation unclear. The former possibility is that cells are haploid. On the images in figure 4B, the cells seem widely spaced out, ruling out that cells are at dyad-tetrad stage and so if the cells are haploids, there are post-meiosis and the technique is no longer suitable to assess for promoter activity in meiocytes.

More worrying, the authors show two cells on the the 2 zoom-in images $(2 n=10$ and $n=5)$ in figure $4 \mathrm{D}$. In figure $4 \mathrm{D}$, both cells are somatic cells - the change in chromocenter number likely reflects a change in the somatic cell cycles but there is no meiocyte and no post-meiotic cell on the 2 zoomin images provided here. There is also no evidence that one of the two cell has reduced ploidy content.

Since the technique described by the authors is intended to test promoter activity in meiocytes, it is thus essential to accurately differentiate meiocytes from somatic cells. Unfortunately, Figure 4 
shows no clear evidence for presence of meiocytes. I suggest the authors to include a chromatin dye - meiotic chromatin is very distinctive and more structured (with formation of the meiotic chromosome axis) that somatic chromatin.

Page 10 and Table 2: It is surprising that most promoters from known meiotic genes give no signal. What meiotic stages were used for the analysis? How are the data comparable and how can we accurately assess the sensitivity of the technique if we cannot clearly state the stage of meiosis? This can easily be resolved by adding a chromatin dye to the tissue preparation. If some of the preparation had immature germ cells then the data presented in Table 2 would be inaccurate and not showing promoter activity in meiosis. It is important that the authors address this major point of concern and demonstrate that the analysis was done on meiotic cells at the same stage (ideally prophase I since the authors used promoters from protein-coding genes important in prophase I of meiosis). Chromatin-stained prophase I of meiosis are very distinctive from later stages of meiosis or from somatic cells and the analysis will be more straightforward.

Figure 6: I don't see the rational for not adding a scale bar for each image. The entire figure is unclear and there is no explanation in the text to help me understand the figure. The data presented here seems to have limited interest and doesn't add more support to the conclusions drawn by the authors and therefore the figure could be removed.

Page 11. The VirD5 expression system is supposed to test promoter activity in meiosis - as suggested throughout the text and in the title. However, in my opinion, this system tests promoter activity during plant life cycle (reproductive) but it will not give indication on cell specificity. The authors acknowledged this limitation in the discussion (p14). The system is based on the reduction of plant fertility, but many reasons could cause this phenotype other than defects in meiosis: defect in the tapetum, post meiosis defects, pollen or ovule viability defects....and therefore, I would describe the system as a method to test promoter activity in floral tissues, irrespective of the cell type.

Page 11 "unexpected for pSMC1, which is more or less a meiosis specific promoter based on available gene expression data". This is not entirely accurate. SMC1 is a well characterised core component of the cohesin ring complex and is expressed in every cells. There are substantial published data studying smc1 mutant phenotype showing pleiotropic effects. This raises some concerns on the validity to use the expression data for the work presented here.

Table 3: Comparing ratio of expression is not informative - the authors should report values of expression for meiocytes and somatic cells separately. What is the definition of reduced fertility? The authors need more clarity here. Is it a quantitative or a qualitative assessment of plant fertility?

Page 12 " quality of seeds" - what does this mean? The authors should use more technical words.

Page 12 " all positions in the silique ... seeds". The authors should use a more quantitative methodology. The observations should be better described for the all section on "VirD5 expression under control of meiosis specific promoters PZYP1A and pSPO11-1" and the claims made by the authors lack scientific support.

I suggest the authors to count the number of seed-set per silique 
"As the flowers did not show any obvious..." The authors cannot exclude an effect downstream meiosis. A lot of meiotic promoters are active in pollen and because the analyses of pZYP1 and pSPO11-1 specificity in Figure 5 and Table 2 are inconclusive, we cannot rule out this possibility "pSPO11-1 is likely to be a very meiosis-specific promoter with at most ..." This is a vague statement with no scientific support. What about the implication of other cell types in the reproductive system?

"Pollen production as well as viability were indistinguishable from wild type plants...". This data suggests that male meiosis is normal, meaning that this technique is not suited to specifically assess gene expression in meiocytes.

"It might have been that female gametogenesis was partially distorted but further experimental ..." This is quite elusive. The authors are claiming to develop a technique to test for promoter activity in meiosis specifically. Unfortunately, it seems that the VirD5 system isn't specific to male meiosis. The authors should investigate female meiosis if they want to demonstrate that their technique can actually be used to test for meiotic promoter activity.

Figure 8 is vague. The technique used for Figure $8 \mathrm{~A}$ is arbitrary. The authors could analyse the data using a quantitative methodology, e.g. seed set per silique, silique length, variation between samples and plants, statistical test... Figure 8B: I don't understand what the interest is to present this figure. If the authors want to show that the seeds have different sizes, it is not apparent on the photos. Figure 8C: It seems that the plants on the left panel with virD5 have slightly retarded growth compared to the plants on the right with the GFP system. The authors should comment on this observation, which may suggest that PSPO11-1 isn't meiotic specific.

Page 13 "We have described two novel strategies to ... expression in meiocytes" The authors need to provide more scientific evidence to support this claim for the reasons mentioned above, or rephrase their claim - e.g. virD5 system could be used to assess floral expression specific while the GFP-based method could be used in complement to assess for cell type specificity

Page 14 "GFP foci localized to the pericentromeric ... ploidy determination" - This statement is not entirely accurate. Centromeric clustering can reduce GFP centromeric foci without changing ploidy level.

Page 14"GFP signals in meiocytes could ... progenitor cells" - This sentence is not clear and need some clarifications.

Is the rationale for developing the new method (or application) clearly explained? Yes

Is the description of the method technically sound?

No

Are sufficient details provided to allow replication of the method development and its use by others?

Partly

If any results are presented, are all the source data underlying the results available to 
ensure full reproducibility?

No source data required

Are the conclusions about the method and its performance adequately supported by the findings presented in the article?

No

Competing Interests: No competing interests were disclosed.

Reviewer Expertise: meiosis, plant reproduction, cytogenetics

I confirm that I have read this submission and believe that I have an appropriate level of expertise to confirm that it is of an acceptable scientific standard, however I have significant reservations, as outlined above.

The benefits of publishing with F1000Research:

- Your article is published within days, with no editorial bias

- You can publish traditional articles, null/negative results, case reports, data notes and more

- The peer review process is transparent and collaborative

- Your article is indexed in PubMed after passing peer review

- Dedicated customer support at every stage

For pre-submission enquiries, contact research@f1000.com 